\title{
"Vivimos y contamos la paz y la guerra”. Caracterización (etnográfica) de experiencias alter comunicativas del sur de Colombia
}

\author{
Andrés Felipe Ortiz Gordillo \\ Waira Nina Jacanamijoy Mutumbajoy (Ingakuna estéreo) \\ Líverman Rengifo Gómez (OCAINA ESTÉreO) \\ Carlos Martínez Cuellar (Piamonte estéreo)
}

$\mathrm{C}^{\mathrm{n}}$ este capítulo se presenta una caracterización de las tres expe-

Criencias alter comunicativas que hacen parte del estudio: Piamonte estéreo (ubicada al sur del departamento del Cauca, en un territorio que se denomina como la Baja Bota Caucana), Ingakuna estéreo (ubicada en la inspección de Yurayaco, municipio de San José del Fragua en el departamento del Caquetá) y Ocaina estéreo (ubicada en el departamento del Putumayo, en la zona que se conoce como el Bajo Putumayo).

La caracterización que se presenta busca dar cuenta, de manera general, de las condiciones sociales, políticas, económicas, culturales y de conflictividad que se presentan en cada uno de los territorios de influencia de las experiencias, y tiene como objetivo situar al lector en los contextos locales que enfrentan los gestores de alter medios, a 
la hora de realizar sus labores comunicativas ${ }^{1}$. Las tres experiencias participantes fueron seleccionadas teniendo en cuenta los siguientes criterios:

- Ubicación: experiencias ubicadas en "zonas de conflicto" social y armado, es decir, que desarrollan labores comunicativas e informativas en zonas del sur del país con presencia regular de actores armados (institucionales y no institucionales).

- Perspectiva comunitaria: experiencias que se inscriban en la lógica de la comunicación comunitaria, alternativa, ciudadana, popular, es decir, experiencias alter comunicativas que surjan como iniciativa de las comunidades locales y que, en este sentido, correspondan a los intereses de estas comunidades.

- Experiencia: medios comunitarios de comunicación con permanencia y experiencia en procesos comunicativos e informativos en el territorio de referencia, con una duración no menor a dos años.

Teniendo en cuenta estos criterios, la caracterización propuesta da cuenta, en su estructura, de tres estrategias de recolección y análisis de datos: la primera formula una mirada etnográfica, resultado del trabajo de campo realizado por los investigadores en dos etapas (meses de junio-julio y diciembre de 2014). La segunda estrategia tiene como fuente el diálogo testimonial realizado en el trabajo de campo y otros encuentros de los investigadores con los gestores de las experiencias. Este diálogo testimonial tiene como base la realización de entrevistas

1 Como se ha señalado desde la introducción, la alter comunicación y los alter medios se deben entender, en el contexto de este documento, como aquel tipo de experiencias desarrolladas al margen de las lógicas y dinámicas desplegadas por el régimen comunicativo hegemónico. Estas son experiencias agenciadas por comunidades locales que autodenominan su accionar alter comunicativo como popular, alternativo, ciudadano, para el desarrollo, para el cambio social, comunitario, etc. La noción de alter comunicación - alter medios busca reunir en una sola denominación a aquellas que han hecho parte del debate y la acción comunicativa subalterna, popular, ciudadana, alternativa y comunitaria (Ortiz, 2014). 
etnográficas, y da cuenta de las formas como estos gestores reflexionan sobre asuntos relacionados con su función como alter comunicadores, las condiciones en las que desarrollan su trabajo alter comunicativo, las nociones que sobre la paz, el conflicto armado, la política y la esfera pública local han construido como resultado del trabajo comunitario que realizan, entre otras cuestiones. La tercera estrategia corresponde a la revisión documental que posibilita, desde el mundo periodístico y académico, establecer contextos de interpretación de las lógicas de desarrollo territorial, comunitario y de conflictividad dados en las zonas de influencia de las experiencias.

La conjunción de estas estrategias posibilitó sintetizar un sentido de lugar "que toma en cuenta la percepción subjetiva que se deriva de vivir en un lugar particular. Este concepto de lugar enfatiza el sentimiento, lo subjetivo que incide en la percepción de la vida social" (Ramírez, 2001, p.31). Igualmente permite reconocer como fuente de información significativa para el estudio, las representaciones que los sujetos (gestores alter comunicativos e investigadores) configuran en relación con sus propias circunstancias y contextos de acción y reflexión situada. Esto porque, como señala Ramírez: "las percepciones [representaciones] subjetivas [promueven] identidades asociadas a ciertos lugares que determinan prácticas sociales y políticas" (2001, p.31), las cuales contribuyen en la determinación de la acción pública de los sujetos en relación con los contextos en los que se encuentran inscritos.

De cara a este sentido de lugar, a continuación se presentan dos mapas en los que se ubican dos cuestiones fundamentales para la comprensión de las experiencias: el primero da cuenta de su ubicación espacial o geográfica. El segundo mapa reseña la presencia de los actores armados (guerrillas, Ejército Nacional y grupos paramilitares / bandas criminales (bacrim)) en los territorios de influencia de las experiencias. El cruce o la sobre posición de estos dos referentes posibilitará al lector entender, de manera un poco más clara, la situación de permanente zozobra e incertidumbre en la que viven las experiencias alter comunicativas, debido a la fuerte presencia militar (de todo tipo) que tienen que enfrentar y oponer en su cotidianidad. 
Figura 1. Ubicación territorial de experiencias de alter medios participantes en el estudio

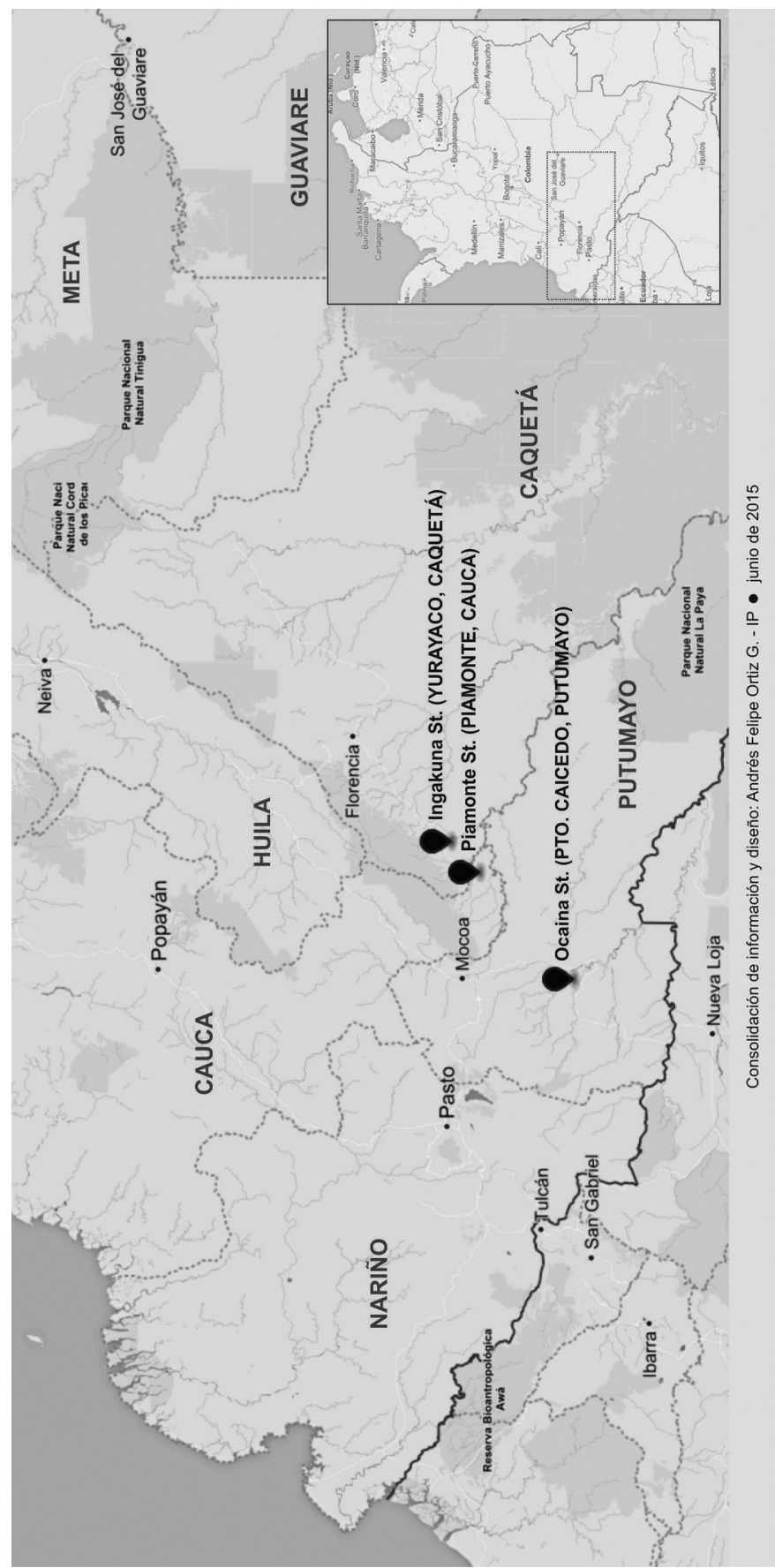


Figura 2. Ubicación de actores armados que hacen presencia en territorios de influencia de experiencias de alter medios participantes en el estudio

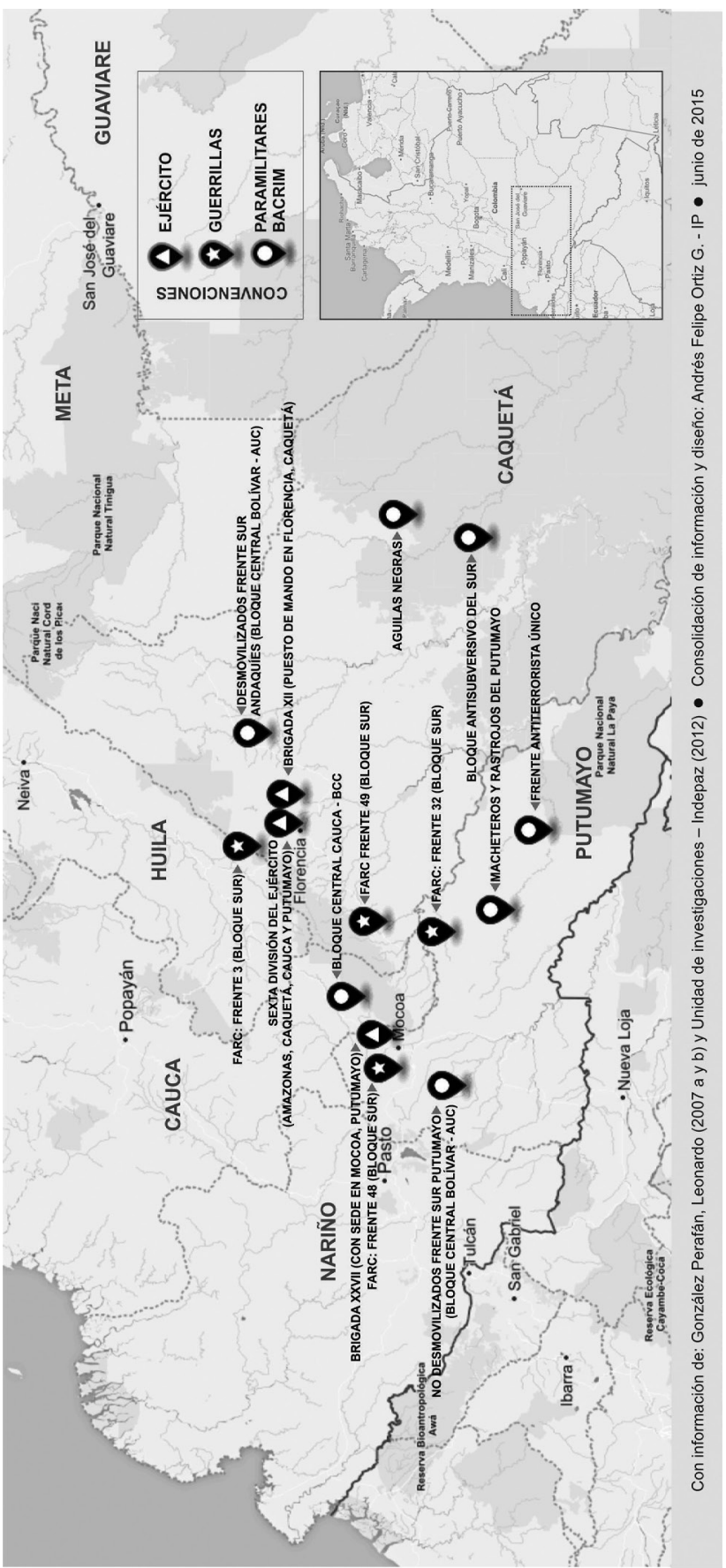




\section{Ingakuna estéreo: voz indígena en el piedemonte amazónico}

Inspección de Yurayaco, municipio de San José del Fragua, departamento del Caquetá.

Emisora Ingakuna estéreo 105.3 FM - Cabildo Indígena Inga de Yurayaco

Junio - julio de 2014

A las 7:30 de la mañana del 29 de junio llegamos a Florencia, Caquetá, después de 10 horas de viaje desde Bogotá. Hacia las 9:30 salimos para Yurayaco (que significa, en idioma Inga "aguas claras"), una inspección del piedemonte amazónico colombiano, donde se encuentra la Institución Educativa Indígena Yachaicuri, que administra la Asociación de Cabildos Indígenas Inga Tandachiridu Ingakuna. Iacha significa, en Inga, sabedor, conocedor. Los taitas son Iachagkuna, los abuelos y abuelas son Iachagkuna. Los Iachagkuna son "los intelectuales" de la comunidad, y su saber es fundamental para su sostenimiento. Los $i a-$ chagkuna son personas - conocimiento que caminan por el territorio, que recrean la vida y la diversidad en él. El nombre de la institución hace alusión, entonces, a la expresión Iachai (conocimiento, saber), e Iacha (sabedor, conocedor, médico tradicional).

En Yachaicuri se ubica la sede de Ingakuna estéreo, una emisora indígena fundada hace más de diez años en las selvas del Caquetá, y que desde hace dos se encuentra inutilizada debido a que parte de sus equipos de transmisión y de su infraestructura fueron saqueados y destruidos por el Ejército Nacional de Colombia.

Una de las gestoras históricas de Ingakuna estéreo es Waira Nina Jacanamijoy Mutumbajoy. Con Waira nos habíamos comunicado por Facebook unos días antes, para avisarle que íbamos para Yurayaco a visitarla y a conversar sobre la emisora. Nos respondió que no se encontraba en el país, pero que habláramos con Alexander Becerra y Jhonny Huaca, dos jóvenes que han estado vinculados a Ingakuna estéreo desde hace años, primero como estudiantes de la institución educativa y, ahora, ejerciendo su liderazgo dentro del Cabildo. También 
podíamos hablar con Flora Maca, la rectora del colegio, y con los profesores de Yachaicuri que han utilizado la emisora como herramienta pedagógica y comunitaria.

Al colegio llegamos hacia el mediodía. Nelsy Méndez Jacanamijoy, la coordinadora, nos recibió con saludos y con rayana, una "sopa" tradicional de los inga preparada con yuca picada, plátano verde rayado, pescado, cilantro de monte y ají, mucho ají. Como íbamos acompañados de dos estudiantes de la Universidad Pedagógica Nacional que venían para quedarse los próximos cuatro meses y realizar sus prácticas pedagógicas de la Licenciatura en Biología, Nelsy aprovechó para ubicarnos a todos en una de las construcciones del colegio. La tarde se nos fue en saludos y recuerdos.

Preguntamos por Flora y nos dijeron que no estaba, que llegaba al día siguiente con Alex Becerra. Jhonny, el otro recomendado de Waira, tampoco se encontraba. Nos dijeron que llegaría al colegio al siguiente día. Nelsy se encontraba organizando la casa (la casa es todo el colegio) para recibir a un grupo de 30 personas de la Pedagógica, que venía para el Segundo Encuentro Educativo Popular. Nosotros nos fuimos a descansar del viaje.

Yurayaco queda al sur de departamento del Caquetá. Es jurisdicción del municipio de San José del Fragua y está muy cerca de la frontera con el Putumayo y el Ecuador. Ahora el Gobierno Nacional está haciendo la vía que se llama Troncal de la selva, que es internacional y está pasando justamente por estos territorios... No es gratis que se está construyendo esta carretera, porque esta zona es prácticamente una zona minera, y una de las problemáticas que tiene el Caquetá actualmente es, precisamente, la oferta de las concesiones mineras, y para hacer estudios sísmicos por todo lado, sea en territorios indígenas o en territorios campesinos. Prácticamente la oferta minera en el departamento del Caquetá ha llevado el caos a las comunidades indígenas, fuera de problemáticas que ya existían, como el tema ganadero que está terminando con selvas amazónicas... En otra época el tema más problemático era el de la coca. 
Todo esto está llevando a que se termine con los territorios ancestrales. Yurayaco, por ejemplo, es uno de los espacios sagrados para los Inga, porque antiguamente nuestros ancianos utilizaban estos territorios como tránsito para venir desde la cuna, desde Mocoa, desde Puerto Limón. Esos eran territorios ancestrales, esto que hoy llaman [los occidentales] el Caquetá, lo que hoy se llama Piedemonte Amazónico, esos eran territorios recorridos por muchos indígenas, mucho antes de la colonia, y eran importantes porque eran espacios de ritualización, de purificación, de cacería, de pesca, de recolección de frutos y de plantas medicinales. Eso era en esos sitios.

Hoy estamos con mucha tristeza, porque realmente con el plan que tiene el Estado a nivel de conectividad con otros países, a nivel latinoamericano a través de esta línea Troncal de la selva, se van a afectar los procesos educativos, sobre todo por los planes de manejo a nivel territorial, porque a través de la carretera entran muchas personas que vienen con otros intereses, vienen en busca de ofertas territoriales para grandes empresas multinacionales, con el fin de buscar empleo y desarrollo para Colombia. Eso es lo que las comunidades hemos venido como pensando, analizando: la fuerte presión que hay frente a estos lugares que para nosotros son sagrados. (Conversación personal con Waira Nina Jacanamijoy Mutumbajoy, 2 de abril de 2014)

Al día siguiente llegaron Florita y Alex. Luego de "adelantar cuaderno", quedamos en conversar por la tarde sobre la emisora, ya que se encontraban en los preparativos del encuentro educativo. Por la tarde, casi noche, pudimos entrevistar a Alex sobre su experiencia en Ingakuna estéreo.

En la conversación salieron algunas anécdotas: que la comunidad colona y mestiza de Yurayaco compró un cable de 1 kilómetro para conectar la emisora con la iglesia, y así poder transmitir la misa y otras actividades que eran desarrolladas por el cura párroco de la inspección. Que el cura párroco de la iglesia católica tenía un espacio semanal de 1 hora en la emisora, y que por el espacio le cobraban 130 mil pesos. Que el pastor de la iglesia evangélica tenía un espacio semanal de media hora, por el que le cobraban 120 mil pesos. Que la emisora se escuchaba en Florencia y en algunos territorios del Ecuador. 
Figura 3. Fotografía de Alexander Becerra, comunicador líder de Ingakuna estéreo

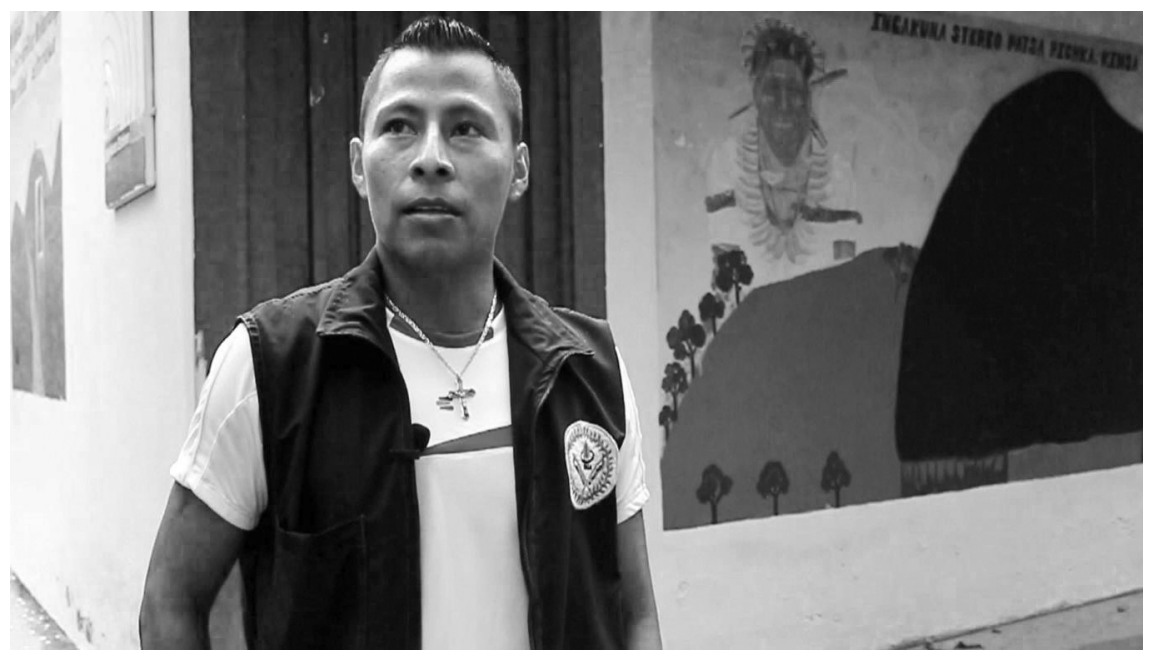

Fuente: Archivo grupo de investigación.

Preguntamos por una situación que nos había comentado Waira unos meses antes en Bogotá acerca del saqueo que los militares habían hecho a la torre de transmisión hacía dos años, motivo por el cual la emisora no estaba funcionando, y que como suele suceder en este país, nadie respondía por los daños, a pesar de las evidencias.

Hicimos la primera entrevista a Alex, y quedamos de vernos con él al día siguiente, a las 7 de la mañana para hacer un recorrido a la torre de transmisión de la emisora, ubicada en el Cerro La Cruz. Por la noche hablamos con Flora, quien nos confirmó las versiones sobre el saqueo y la destrucción de la emisora. Quedamos en recolectar la mayor cantidad de información y evidencias para hacerlas llegar al Ministerio de Tecnologías de la Información y las Comunicaciones (MinTic), a organizaciones de defensa de procesos comunicativos y a periodistas amigos ubicados en Bogotá, pues en el municipio de San José del Fragua al que pertenece la inspección y con el mismo Ejército Nacional, no se veían posibilidades para la restitución de los equipos para el funcionamiento de la emisora, cuyo costo aproximado es de 30 millones de pesos. 
Al día siguiente, a las 7 de la mañana, nos vimos con Alex, quien nos dijo que no podía ir al recorrido porque se encontraba realizando actividades del encuentro pedagógico que iniciaba a las ocho de la mañana. Nos presentó a Jhonny Huaca, con quien iniciamos el recorrido. Antes de salir, el Alguacil del Cabildo nos advirtió: "no se vayan a desviar del camino porque eso por allá está minado... Ustedes para qué van a subir por allá, eso está abandonado y es peligroso. Si suben tengan cuidado y no se salgan del camino..."

Nos comentaron también que ellos habían dejado de subir a ese espacio porque en varias ocasiones, cuando subían el ganado para pastar, encontraron minas antipersona, de esas que llaman "quiebrapatas" y también de esas que llaman "sombreros chinos", aquellas que tienen como un alerón que se ubica sobre el suelo, simulando un sombrero. Del miedo que causa pensar que alguno de ellos o de sus animales pudiera caer en una mina, prefirieron dejar de subir.

\section{La torre de transmisión, el saqueo y la demanda}

Figura 4. Fotografía de Jhonny Huaca en el Cerro de La Cruz, donde se encuentra ubicada la torre de transmisión de Ingakuna estéreo

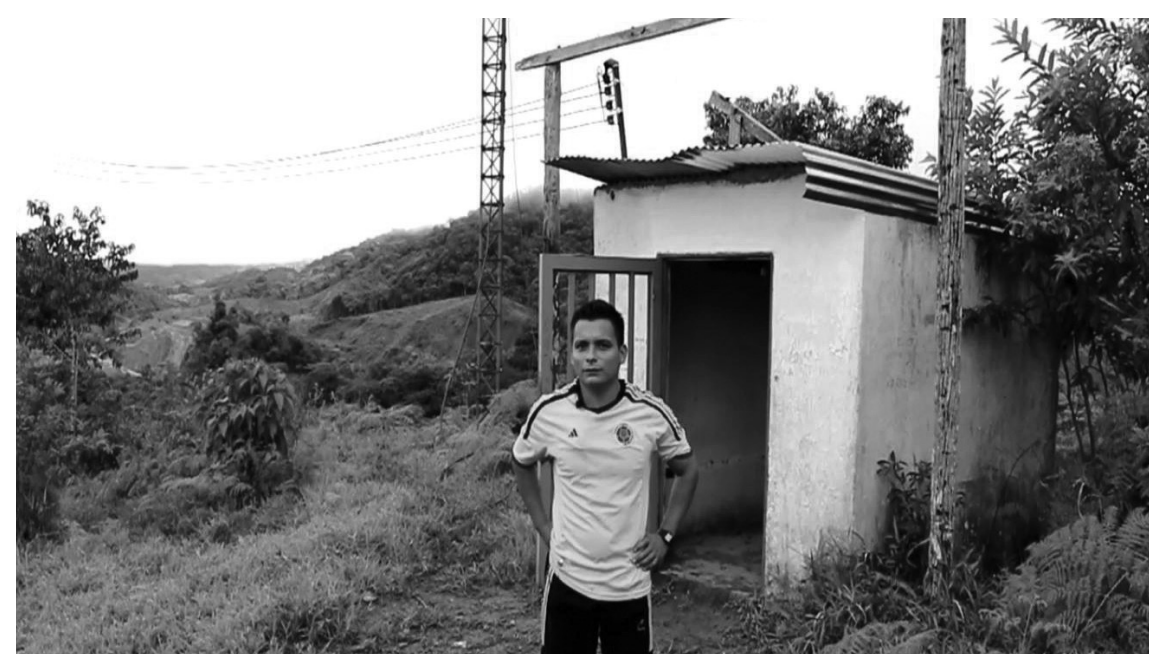

Fuente: Archivo grupo de investigación. 
Hacía el año 2012 el cabildo demandó al Ejército Nacional ante la Personería Municipal, por la ubicación de la tropa en el cerro El Alto de la Cruz (Nucanchipa alpa mama, nuestra tierra, como le dicen los Inga a todo su territorio), donde estaba la antena de transmisión de la emisora. Al principio el coronel del Ejército reconoció los hechos que afectaron la torre (pelaron y cortaron los cables, saquearon la torre, rompieron una teja, la puerta de la cabina, la chapa, etc.), pero una vez supo los costos de los arreglos (más de 30 millones de pesos), señaló que había que revisar quiénes habían sido los responsables. El proceso se embolató, hasta la fecha.

Actualmente tenemos un problema: la emisora está produciendo, pero no está al aire, porque justamente nuestra antena de emisión se encuentra en un cerro [de la Cruz], y este cerro es muy estratégico para los grupos armados que llegan a la región. Por la visibilidad que tiene para las montañas, para los planos, para todo lugar, el Ejército se ubicó allí y empezaron a pelar los cables, empezaron a hacer cortos, y ya últimamente desaparecieron los equipos que teníamos en la torre de emisión. (Conversación personal con Waira Nina Jacanamijoy Mutumbajoy, 2 de abril de 2014)

Figura 5. Imágenes de saqueo de equipos e infraestructura de Ingakuna estéreo por parte del Ejército Nacional
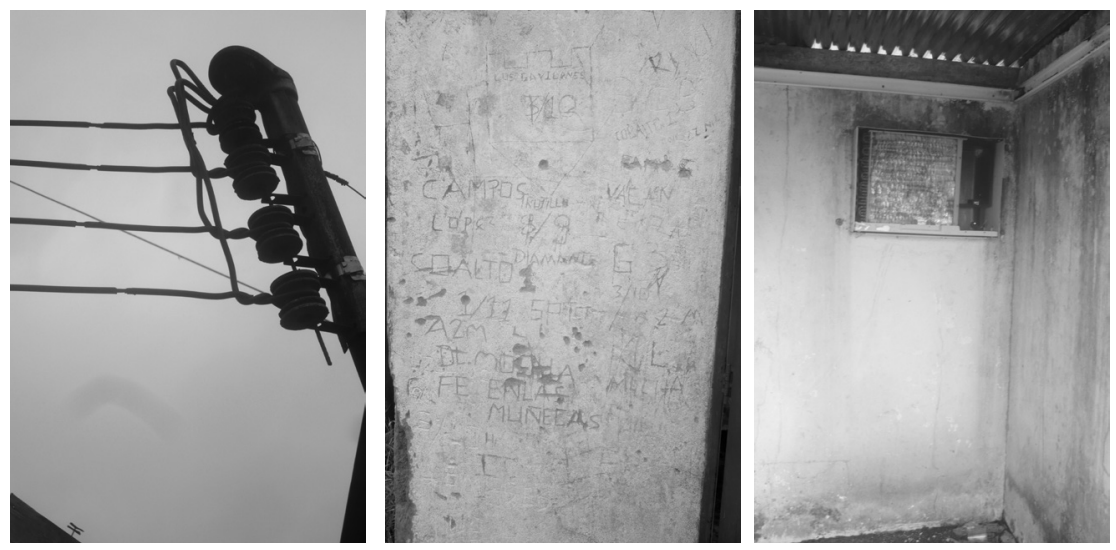

Fuente: Archivo grupo de investigación 
Las autoridades del cabildo solicitaron al Ejército que se retirara de la zona donde se ubicaba la torre de transmisión, argumentando que estos son territorios sagrados, pertenecientes al resguardo. Desde este sitio el Ejército sostenía combates con la guerrilla de las Farc-ep, quienes se apostaban en uno de los cerros al frente de la Cruz, con el grave inconveniente de que, entre cerro y cerro se ubica la institución educativa indígena Yachaicurí, de la cual hacen parte los gestores de la emisora.

Ahorita está empezando ese proceso [de restitución del derecho que a la comunicación tiene la comunidad, por la vía de la restitución de los equipos y la infraestructura afectada]. El alcalde no ha querido moverlo mucho, por el peligro que hay. Hasta ahorita va un derecho de petición, pero ellos [los militares] quieren arreglar solamente las consolas. Nosotros les dijimos: el Ejército tiene que dejar funcionando la emisora como estaba. No sabemos qué pasó ahí porque no hay pruebas de que ellos se hayan llevado los equipos, pero sí hay pruebas de que ellos hicieron los cortos y de que ellos estuvieron ubicados ahí en el cerro, y que ellos no nos dejaban entrar a nosotros a la torre sin permiso.

Nosotros para poder prender la emisora teníamos que pedir permiso de ellos, y en un momento que fue muy conflictivo, que hubo muchos enfrentamientos entre el Ejército y la guerrilla, pues fue un tiempo que estuvo apagada la emisora. Nosotros dejamos de ir por el peligro que había, de pronto de minas, y ya cuando volvimos no encontramos nada, estaba todo destruido. Nosotros fuimos a hacer unas grabaciones de donde estaban los del Ejército. Ahorita lo que le estamos diciendo a ellos es que nos devuelvan la emisora, que nos devuelvan todo. (Conversación personal con Waira Nina Jacanamijoy Mutumbajoy, 2 de abril de 2014)

La población civil (en este caso los indígenas Inga que habitan el colegio Yachaicuri: profesores, administrativos, 85 estudiantes internos y 40 externos) ha quedado en medio de los combates. En mayo de 2014, en uno de los enfrentamientos, cayó un "petardo" en el colegio, en el espacio ubicado entre la emisora y la casa del profesor Evirley (este espacio es de unos 25 metros). Flora Macas, la rectora del colegio, dice que en 
varias oportunidades les ha tocado resguardarse de los enfrentamientos en los baños, que son los únicos espacios de las construcciones fabricados en material (ladrillo y cemento).

Pero por ejemplo encontrar minas alrededor nuestro, alrededor de nuestra institución educativa con más de 50 niños, es muy difícil la situación. Encontrar minas en nuestro territorio nos implica, además, llamar a la Personería, llamar al Ejército: "ique por favor no se hagan ahí!”, o a la guerrilla: “por favor respeten este es un sitio donde nosotros estamos moviéndonos, donde nosotros estamos desarrollando un proyecto en lo educativo; ustedes nos están afectando". De ponerle notificación al alcalde, de llamar a la Policía... y saber que nadie hace nada, y que les de miedo hablar de esos temas. $\mathrm{O}$ sea, ¡eso es grave!, ¿cierto?, eso es grave; significa que a nivel de departamento, y sobre todo en este municipio, para que le pongan atención a una situación debe haber 100 muertos, 80 muertos, 50 muertos, o por lo menos 10 indígenas masacrados, como les pasó a los Coreguajes, que les mataron a yo no sé cuántos, y solo así les pusieron cuidado. Entonces, ¿qué es lo que están esperando?, ¿que haya una masacre para decir: esto es importante? (Conversación personal con Waira Nina Jacanamijoy Mutumbajoy, 2 de abril de 2014)

A la comunidad le ha tocado aprender a vivir con los ataques de los actores armados, tanto institucionales como insurgentes. El gobernador mayor del cabildo, Carlos Enrique Cortés Jamioy, y otras personas del cabildo (Alex, Jhonny, Flora, Evirley) dicen que ellos no están “ni con los unos ni con los otros", que "no nos importa si son de izquierda o de derecha", lo que quieren es no verse involucrados en el conflicto, y que como comunidades indígenas les interesa mantenerse al margen del conflicto, pero resguardando y velando por sus derechos, sobre todo en lo que tiene que ver con el respeto y el rescate del territorio.

Esa es la lucha más fuerte de la comunidad: mantener y recuperar el territorio, pues "con territorio los indígenas tenemos vida", dice Flora, mientras que en una pared del colegio hay un mural que expresa: El corazón y el pensamiento de Nukanchipa Alpa Mama. 
Somos territorio. El suelo es la carne, la montaña es la piel, los ríos son la sangre, las quebradas son las venas, el rastrojo son los huesos, los animales son la alegría y nosotros somos los ojos.

Es precisamente esa lucha por recuperar el territorio de manos de grupos armados, legales o ilegales, lo que ha hecho que, por ejemplo, integrantes del Ejército Nacional de Colombia los señalen como colaboradores de la guerrilla, porque dicen que: "son los indígenas Inga los que no quieren que el Ejército esté en ese territorio..." El Ejército dice que "no se bajan de ese alto porque es un lugar estratégico, que si se hacen en otro lugar, quedan en peligro de una emboscada por parte de la guerrilla".

Cuando yo estaba empezando a trabajar en la radio, aparecí amenazada en el 2003 como auxiliar de la guerrilla. Como que me ha demandado alguien, un NN, en Bogotá, en la época de Uribe. ¡Y bueno!, yo creo que se siguen repitiendo muchas cosas de estas a nivel de departamento. (Conversación personal con Waira Nina Jacanamijoy Mutumbajoy, 2 de abril de 2014)

\section{El sostenimiento (social y económico) de Ingakuna estéreo}

Una tarde fuimos a la sede de la emisora con Jhonny y Alex. Ellos comentan que aunque el MinTic les dio los equipos, fue experimentando como aprendieron a manejarlos, ya que no hubo procesos de formación para dicho manejo y, como dice Waira: "dañando es que se aprende".

La experiencia ha sido muy buena desde que inicié en el colegio... Yo estudie dos años en el colegio y empecé a hacer prácticas con un técnico que tenía, buscando motivar a los pueblos indígenas. Entonces a mí me dejaron hacer programas indígenas, culturales, sobre el idioma Inga, y así inicié a hacer programas para motivar a los jóvenes que nuestro idioma es importante, y eso fue lo primero que yo realice como artesanalmente. (Conversación personal con Alexander Becerra, 30 de junio de 2014) 
La infraestructura donde funciona la emisora fue financiada, hace 10 años, por una organización denominada Instituto de etnobiología, que ha cambiado de nombre y hoy se conoce como la ACT (Amazonia Conservation Team). Esta infraestructura es amplia. Se compone de 4 espacios (un rectángulo dividido en 4): hay un "espacio de recibimiento" (que hoy funciona como bodega para unos colchones donados por la ACT que, dicen, va a construir 5 "complejos habitacionales" para los estudiantes internos del colegio. Ya se ha construido uno de los complejos, que fue "donado" por el guitarrista del grupo de rock Bon Jovi), dos espacios para Master y una cabina de grabación en muy buenas condiciones.

Figura 6. Fotografía de Waira Jacanamijoy en la emisora

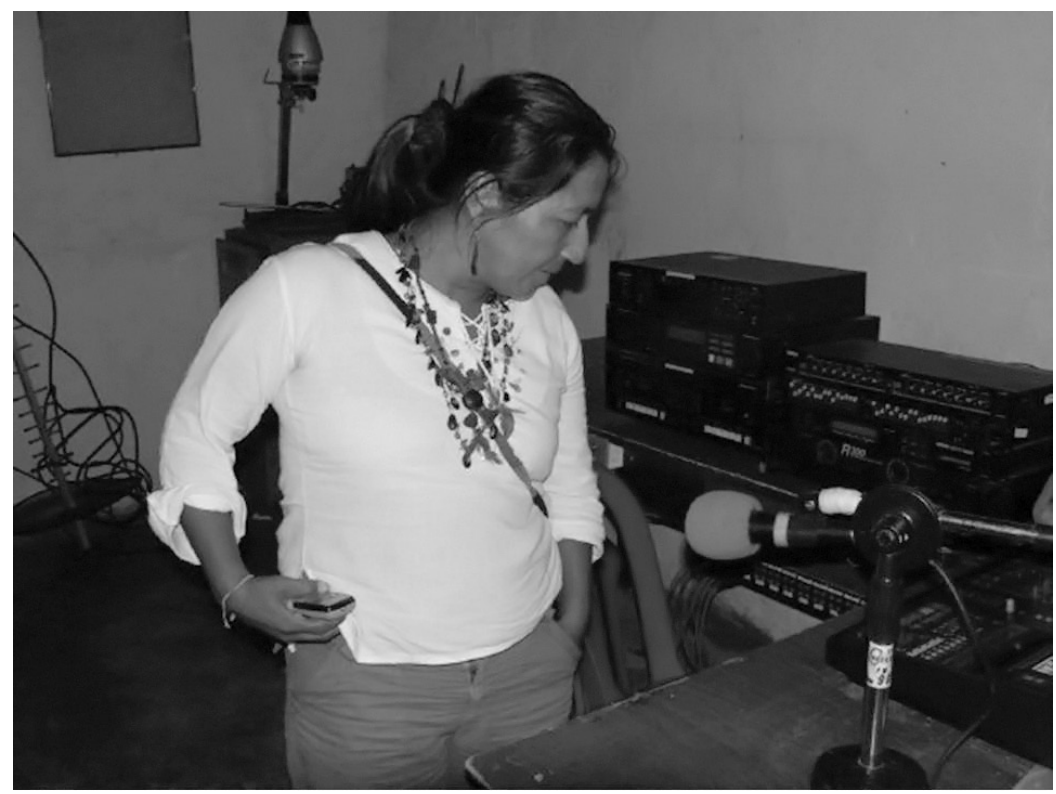

Fuente: Archivo Ingakuna estéreo 
Figura 7. Fotografía de Jhonny y Alex en las instalaciones de Ingakuna estéreo

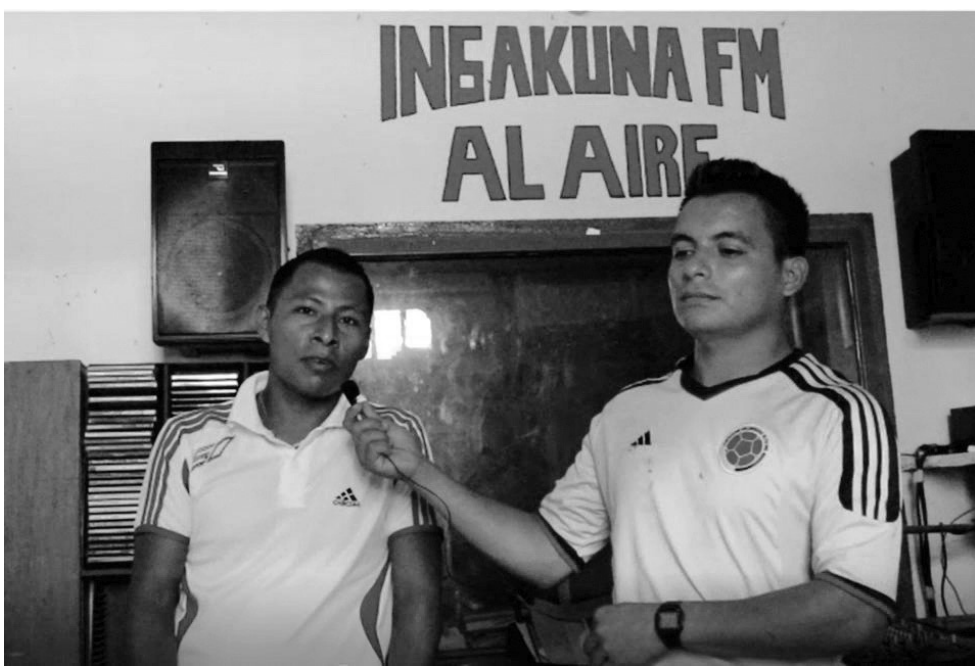

Fuente: Archivo equipo de investigación.

Figura 8. Plano de la sede de la emisora Ingakuna estéreo

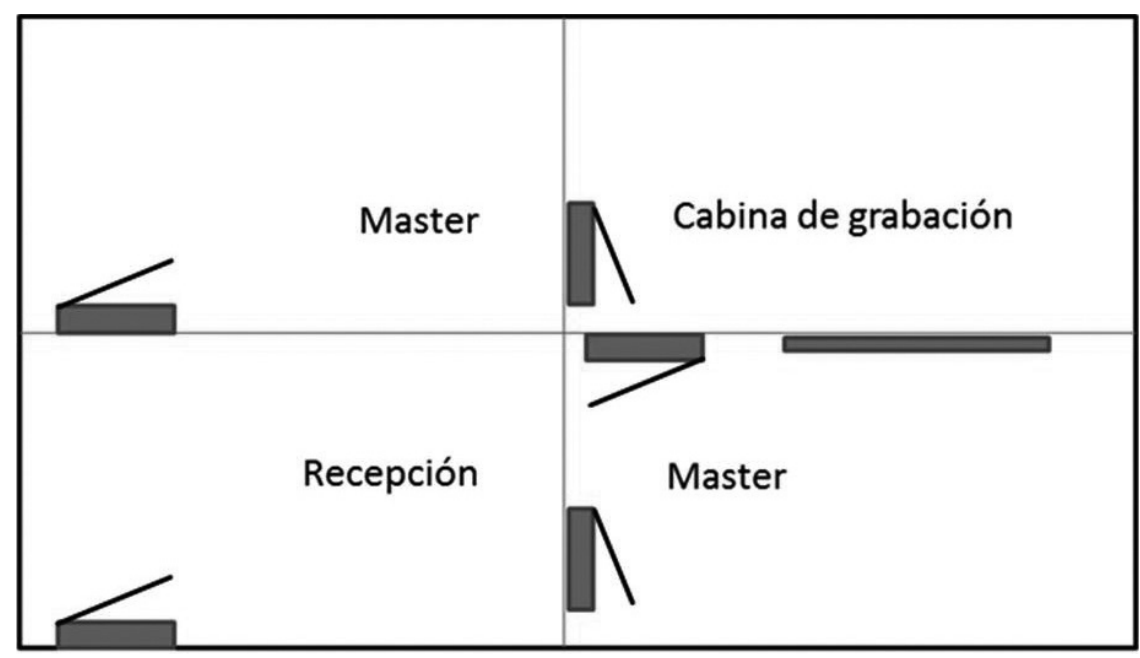

Fuente: Archivo equipo de investigación.

Los equipos fueron entregados por el Ministerio de Comunicaciones (hoy MinTic) a la Asociación Tangachiridu Ingakuna que administra 
la institución educativa. La infraestructura fue donada por ACT y el trabajo fue desarrollado por los Inga. Han contado con algunos apoyos, por la vía de proyectos, de ALER (Asociación Latinoamericana de Educación Radiofónica), el Ministerio de Cultura, el de las Tecnologías de la Información y la Comunicación, y en algunos encuentros han "hecho amistad" con radialistas comunitarios de otras zonas del país, entre los que se encuentran los compañeros de Suba al Aire, una de las siete emisoras comunitarias que en 2010 entraron en funcionamiento en Bogotá.

Además de estos apoyos, la emisora se financiaba con aportes de pauta publicitaria de los comerciantes de la zona. Se cobraba por "número de pasadas", es decir, número de veces que aparecía la mención publicitaria en la parrilla de programación. Otra forma de financiación eran los mensajes: por cada mensaje se cobraban 2 mil pesos, y cuando los mensajes eran muy largos o traían varios mensajes en uno, se cobraban 3 mil.

Con los aportes de la pauta publicitaria y los mensajes, se cubrían costos de sostenimiento de la emisora, sobre todo lo que tenía que ver con el valor de la luz eléctrica. Al inicio de la experiencia, el costo del servicio de energía era de 800 mil pesos (por el tipo de conexión "trifásica”). Cuando modificaron los transformadores de la asociación y se hicieron arreglos en la torre de transmisión, los costos mensuales de luz se disminuyeron a 250 o 300 mil pesos.

En lo que tiene que ver con la sostenibilidad social y comunitaria, Jhonny Huaca menciona que el mayor trabajo de la emisora ha estado relacionado con el fortalecimiento cultural, abordado desde los componentes del plan de vida del pueblo Inga: territorio, medicina tradicional, cultura, fortalecimiento del idioma, organización y justicia propia. A partir de estos temas se ha realizado una amplia producción radiofónica, desde programas que promueven el cuidado y conservación de las aguas, la disminución del consumo de agroquímicos y la recuperación de semillas.

Otro componente fuerte es el fortalecimiento del uso del idioma Inga mediante producciones realizadas exclusivamente "en idioma", y a partir de entrevistas y jingles o spots radiofónicos en los que se transmiten mensajes relacionados con el medio ambiente, la cultura y las 
tradiciones, la educación propia, la memoria ancestral y problemáticas cotidianas de la comunidad. Estos contenidos están directamente relacionados con el trabajo pedagógico que se implementa en la Institución Educativa Yachaicuri, donde también se realizan programas que recrean historias relacionadas con el pueblo Inga, como la del Taita Apolinar Jacanamijoy, quien fue uno de los primeros pobladores de la zona.

\section{Las problemáticas que se enfrentan}

Los problemas reconocidos como los de más impacto para la comunidad son:

Problemática uno: El conflicto armado (presencia de las Farc-ep, del Ejército Nacional, de paramilitares y de bandas criminales (bacrim). Frente a esta problemática no se habla públicamente. Hay que preguntar sobre el tema para recibir respuestas que muchas veces son generales. Se mencionan a los actores de la guerra pero no se ahonda en el tema ni se referencian casos, acontecimientos, hechos, relacionados con el conflicto armado.

Nosotros en las noticias, digamos en la parte que era política, casi no nos metemos, o sea, si la noticia es a nivel general del Caquetá, la transmitimos, pero hay algunas que no, porque buscamos noticias que no nos involucren mucho, porque recuerde que aquí estamos en una zona, como dicen los medios nacionales, zona roja, y pues a nosotros nos toca cuidarnos mucho, porque si no, también el conflicto nos afecta y puede afectar a la asociación. (Conversación personal con Alexander Becerra, 30 de junio de 2014)

La cosa es que el discurso, a veces de la guerrilla o a veces del Ejército es: “¿ustedes a qué bandos pertenecen? ¡O son de la derecha, o son de la izquierda!”, y nosotros: “¡ni mierda, no somos de nadie!, nosotros lo que queremos es construir, desarrollar nuestras formas propias de trabajar la tierra, las formas de educarnos, las formas de las ceremonias." La política nos tiene así de revueltos, pero lo que hemos sostenido es que nosotros no somos ni derecha, ni izquierda. (...) Le hemos explicado a la guerrilla esa parte... que respete, que respete nuestras tradiciones, nuestra forma 
de ver el mundo, y lo mismo le hemos dicho al Ejército, la misma cosa le hemos dicho a ellos: ique nos respeten, que nos dejen desarrollar el proyecto en lo educativo, que no se hagan en estos lugares!@ Pero a nosotros nos tienen en la mira, no sabemos por qué, pero[...] (Conversación personal con Waira Nina Jacanamijoy Mutumbajoy, 2 de abril de 2014)

Hay que decir que en el territorio circulan una serie de "panfletos", que funcionan como artefactos / dispositivos simbólicos para generar terror e incertidumbre. Las amenazas son proferidas sobre líderes de las organizaciones sociales y movimientos políticos, a quienes se les acusa de ser "brazos políticos" del enemigo. Esta situación genera, en lo personal, miedos y desconfianzas. En lo social, las amenazas contribuyen al fraccionamiento y la disminución de la acción público política. En lo organizativo también se generan un repliegue, un cierto aislamiento, una parálisis de la acción política y del agenciamiento del debate público "mientras pasan las amenazas". Son, en este contexto, múltiples las afectaciones que se generan en los procesos organizativos locales por parte de los actores armados, a partir de estrategias que pueden ser consideradas en el marco de la guerra como sutiles (que tal es el caso de los panfletos), pero que tienen una efectividad mayúscula de cara al posicionamiento de los actores de la guerra en los territorios:

En el Caquetá durante los meses de abril y mayo circularon cinco panfletos firmados por el Bloque Andaki de las Águilas Negras, dirigidos contra organizaciones y líderes que integran la Marcha Patriótica. En los panfletos se acusa a más de 20 líderes sociales y a las organizaciones Coordinadora Departamental de Organizaciones Sociales, Ambientales y Campesinas del Caquetá (Coordosac), Unión Patriótica, Partido Comunista, Caguán Vive, entre otras, de conformar el brazo político de las Farc. Las amenazas les dan un ultimátum a sus representantes para salir del departamento. (Paredes y Torres, 2014) 
Figura 9. Panfletos que han circulado en el departamento del Caquetá entre 2012 y 2014
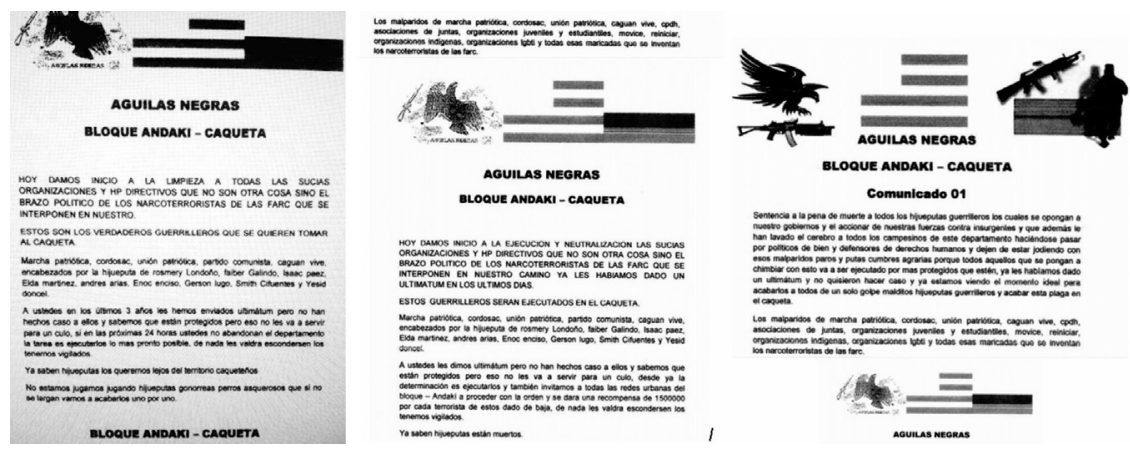

Fuente: Paredes y Torres (2014).

Problemática dos: El conflicto minero energético. Este es un tema de debate público en el municipio. La comunidad está dividida: los indígenas se niegan a la entrada de las petroleras debido a la afectación que generaría en su territorio. Por ejemplo, el Taita Patricio Jojoa (médico tradicional y mayor de la comunidad) comentaba en una reunión, que la reducción del territorio del resguardo indígena Inga de Yurayaco, implicaba disminuir la posibilidad de encontrar plantas medicinales como el Yagé, vital para sus prácticas ancestrales y para el sostenimiento de la comunidad en sus relaciones con la vida, el ambiente y el territorio.

De un tiempo atrás vinieron unas petroleras a hacer un estudio sísmico, y ahorita están preocupados porque resulta que nosotros no dejamos permiso para que entren a mirar nuestro territorio, porque según ellos dijeron, por aquí había un pozo. (Conversación personal con Waira Nina Jacanamijoy Mutumbajoy, 2 de abril de 2014)

Frente a este conflicto son varios los momentos de desarrollo. Con la llegada de los procesos de exploración petrolera, los Inga aceptaron algunas de sus actividades y condiciones: "Teníamos cerrado el ñawi (ojo)", dijo el profesor Evirley en una conversación. Luego, cuando "afinaron el nawi" y se enteraron de las afectaciones que la industria extractiva de petróleo generaba sobre sus territorios ancestrales, comenzaron el proceso de resistencia: “¿Quién puede vivir sin agua, tierra, 
aire? Por la defensa de nuestros territorios digamos no a las multinacionales", aparecía en una fotografía que referenciaba una pancarta utilizada en los procesos de resistencia. La foto estaba ubicada en uno de los tambos del colegio.

Figura 10. Fotografía de consignas reivindicativas de la autonomía territorial en contra de las multinacionales. Ubicada en el colegio Yachaicurí de la Asociación de Cabildos Tandachiridu Inganokuna en Yurayaco, Caquetá

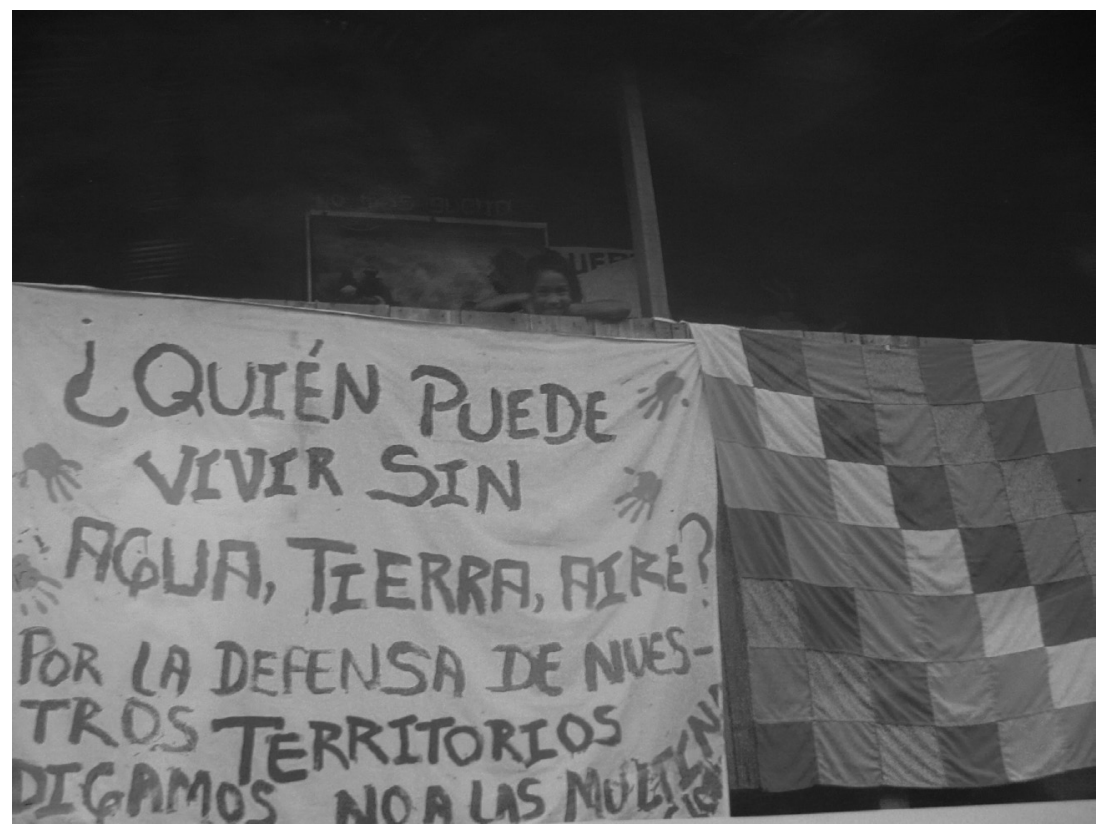

Fuente: Archivo grupo de investigación.

Otros actores del municipio, sobre todo los "colonos" (los blancos), han aceptado con mayor facilidad las condiciones de "las petroleras" o "la compañía", como por allí se les dice. Se ha aceptado "la llegada del desarrollo y del progreso", representado en empleos temporales donde los otrora campesinos sirven como mano de obra "no calificada" en los procesos de exploración. Los empleos ofrecidos son "bien pagos", pero no representan estabilidad laboral. Al contrario, son empleos temporales que pueden durar tres o seis meses. 
El tema petrolero también es otro conflicto fuerte que tratamos en la emisora, porque son cosas de multinacionales que vienen a afectar el medio ambiente y nuestras costumbres. (...) Hay un conflicto que finalmente afecta más que todo a las comunidades de esta región en lo que tiene que ver con la diversidad cultural de los pueblos indígenas, porque esta zona ha sido muy intervenida por los proyectos petroleros, porque le tienen mucho interés a esta zona, y entonces eso ha sido como un factor conflictivo que ha generado incluso peleas con las comunidades campesinas, porque ellas dicen que la petrolera es fuente de empleo y otras cosas, pero no miran los problemas ambientales, culturales y sociales que eso trae. (Conversación personal con Jhonny Huaca, 30 de junio de 2014)

Problemática tres: La carretera. Se viene construyendo la carretera troncal Marginal de la selva o Vía al Sol, que comunicaría la Amazonía: la colombiana con la peruana y la brasilera. Con esta carretera, dicen los Inga, se están afectando territorios de reserva biológica y ancestral. Es una infraestructura dispuesta para el comercio. Como en el caso de la industria minero energética, no tenían muy claras las implicaciones de estos procesos. Cuando llegaron los funcionarios e ingenieros a presentar la propuesta, los Inga “tenían cerrados los ojos”, según dice el profesor Evirley, y firmaron el permiso para su desarrollo.

Ahorita con la construcción de esa carretera, en esta parte de la selva se está afectando hartísimo la naturaleza. Por ejemplo, con esa construcción están destruyendo muchas cosas, y se están viviendo derrumbes que antes no había, mejor dicho, en donde no había, y ahoritica ya existen esas afectaciones, sobre todo por lo que han cortado muchos árboles y eso desgasta el suelo. (...) Y también se están yendo los animales, ya es difícil la cacería y tener para comer, aunque nosotros tenemos mucho cuidado con los animales, pero con lo de la carretera como que se están yendo... (Conversación personal con Alexander Becerra, 30 de junio de 2014)

Para el caso del resguardo de San Miguel, en el Caquetá, la carretera "pasa por el medio y lo parte en dos", dice el profesor Evirley. 
También se han generado derrumbes permanentes en la zona, producto de la construcción de la carretera, con lo que se empieza a "mover la tierra de los resguardos". En una caminata por Yurayaco en medio de la lluvia, del barro y de las múltiples volquetas que circulan por la calle principal, Jhonny Guaca dice: "en lugar de arreglar, la carretera se ha tirado los caminos”.

\section{Piamonte estéreo: voces comunitarias en la Baja Bota Caucana}

Municipio de Piamonte, Baja Bota Caucana, Sur del departamento del Cauca.

Emisora Piamonte estéreo 88.4 FM

Julio de 2014

El miércoles 3 de julio, a las 8 de la mañana, iniciamos el recorrido hacia el municipio de Piamonte, al sur del departamento del Cauca. La noche anterior había sido la del diluvio: hacía más de 12 horas que no paraba de llover a ritmo de tormenta, y los ríos y quebradas se encontraban desbordados. Ya nos habían advertido que el viaje hacia Piamonte desde Yurayaco, en el Caquetá, que en condiciones normales implicaba un recorrido de dos horas y media aproximadamente, se podía prolongar un par de horas más.

Los aguaceros, propios de estos meses en la región, tenían inundados los potreros y crecidos los ríos. Las quebradas que en épocas de verano se pueden superar a pie sin problema, ahora llevaban cauces de mediana afluencia y bien se podrían llevar a un hombre a rastras. Hacia las diez de la mañana, el bus "Confort" de la empresa Coomotor Florencia y otros vehículos no pudieron sortear uno de los cauces: "como mi ruta es circular, yo me devuelvo de una vez porque no vale la pena estarse aquí parqueado. Ustedes verán si los devuelvo y los dejo en Zabaleta [una pequeña inspección del departamento del Caquetá, que recién habíamos pasado]”, nos dijo el conductor a los tres pasajeros que quedábamos. 
Nos devolvimos para Zabaleta, a 10 minutos del paso restringido. Allí nos recibió la negra Esperanza, una de esas amigas que quedan de los viajes anteriores por la región. Desayunamos en su restaurante, uno de los dos que hay en la inspección, donde hace una fuerte presencia el Frente 49 de las Farc-ep. "Comandante Jorge Briceño: estamos cumpliendo", se lee en el muro de una casa cercana a la iglesia. Seguía lloviendo, aunque ahora con menos intensidad. La de ahora era una llovizna que igual no dejaba ver el sol que nos había sido esquivo desde la llegada.

Pasado el mediodía vemos asomar desde el restaurante de la negra, a "el mixto" (una chiva) que tiene como destino el puerto conocido como El Jauno, sobre el Río Caquetá, en límites entre el departamento del Cauca y el Putumayo. Hacemos el pare y retomamos el viaje, a ver si ya han bajado las quebradas y se puede pasar hacia Piamonte. Efectivamente la primera quebrada (que en la mañana no se pudo atravesar) permitió el paso, lo mismo otras dos o tres que están de camino. Parecía que el recorrido se podría culminar sin más inconvenientes, pero unos metros antes de llegar al Fragua Grande, un río hermoso cuyas aguas claras de verano dejan ver las piedras del fondo. En el sector de Puerto Bello (Caquetá) había un derrumbe... Por las lluvias intensas se desbarrancó un pedazo de montaña, quedando un reguero inmenso de piedras, lodo y árboles, y una banca (carretera) fracturada.

Figura 11. Derrumbe en el sector de Puerto Bello, Caquetá

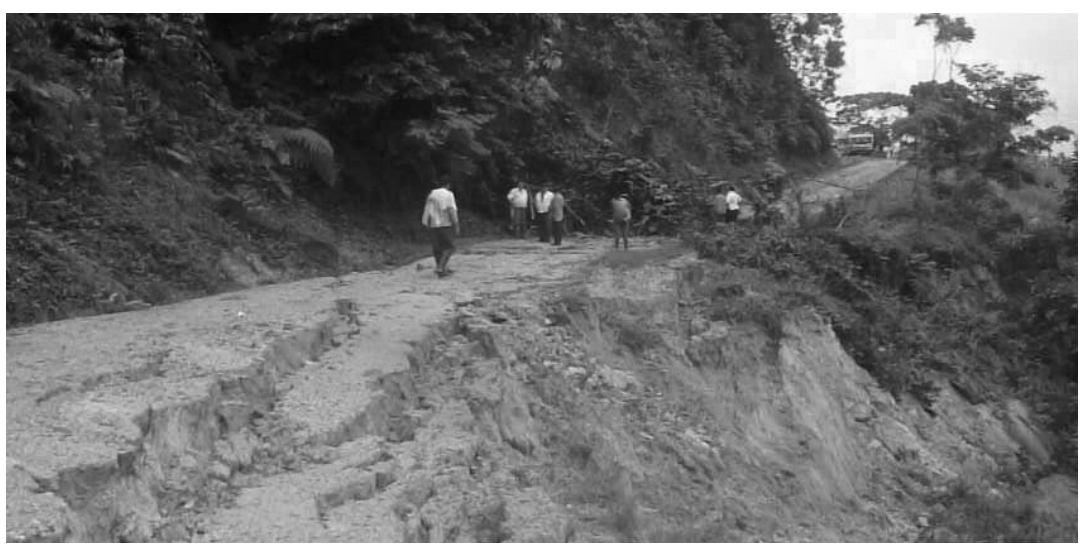

Fuente: Archivo grupo de investigación. 
A parar nuevamente. La gente del mixto se bajó. Alguien dijo que se podía pasar a pie y que en el otro costado del derrumbe se podía tomar el bus que venía y que ya se iba a devolver hacia Piamonte. Cogimos las maletas, pasamos a pie el lodo y tomamos un nuevo bus (el mismo "Confort" de Coomotor que nos había dejado en Yurayaco unos días antes).

A las 3 de la tarde llegamos a Piamonte, en un viaje que había durado siete horas. Por estas selvas eso de "las condiciones normales" no funciona. Por estas tierras, buena parte de los referentes que sirven para ubicarse y transitar y vivir en las grandes ciudades, se ven replanteados de manera permanente. De hecho, una de las condiciones que nos llevaron a formular este proyecto de venir a ver cómo es que funcionan los medios de comunicación comunitaria en "las zonas de conflicto", es precisamente aquella de "revalorar las condiciones normales" que se imponen a la hora de evaluar las realidades conflictivas del país.

Cuando planteamos el proyecto "Viviendo y contando la paz y la guerra...”, uno de los presupuestos tenía que ver, precisamente, con el hecho de intuir que lo que funciona en las ciudades capitales, en los centros del desarrollo y del poder, no puede tener un mismo desarrollo en "las zonas apartadas del país". Y hasta esta parte del camino, las evidencias así lo demostraban: el celular no tenía señal, la gente trasteaba la remesa del mes (el mercado) de un bus a otro en medio del barro, mercado que había sido comprado en alguna cabecera municipal a muchas horas de distancia y que ahora, luego de interminables horas de viaje y múltiples proezas, llegaba a alguna casa campesina o indígena en alguna vereda apartada de los "beneficios del desarrollo"...

Llegando a Piamonte, un municipio del sur del departamento del Cauca fundado a mediados de la década del noventa (del siglo $\mathrm{xx}$ ), en el contexto de los paros cocaleros y de la resistencia campesina e indígena contra "el desarrollo petrolero", llamamos a Carlos Martínez Cuellar, el director de la emisora comunitaria Piamonte estéreo 88.4 FM. 
Nosotros logramos, a raíz de aprovechar en algún momento algunas protestas sociales que hubieron en el 94 y posteriormente en el 96 [en el contexto del "paro cocalero"], se logró que la comunidad se reuniera no solamente con el objetivo de decir que era necesario que se diera una transformación al sector agrario, sino que también a nosotros se nos tuviera en cuenta en la búsqueda de ser un municipio, por lo tanto en esos meses que estuvimos, por decirlo así, acantonados en una de las vías haciendo de alguna forma difícil el trabajo a las petroleras que hacen presencia en nuestro municipio, dio origen para asentar a los mandatarios de turno, en este caso el Gobernador del Departamento del Cauca y líderes sociales de la comunidad, de la Baja Bota Caucana, para buscar la manera de que fuera posible convertirnos en municipio. Eso se logró a través de una resolución, y a partir de noviembre del 96 se dio la Ordenanza 024 que permitió crear el municipio y, desde ese entonces, Piamonte ha venido creciendo. Nosotros desde un principio participamos en el proceso de lograr que Piamonte fuera municipio, para buscar que el gobierno hiciera presencia en esta zona que está muy alejada de la capital del departamento del Cauca, porque acá la gente se siente más caqueteña que caucana, y por estar tan lejos del poder departamental, Piamonte no era tenida en cuenta para nada. Y así logramos ser municipio y, pues, consideramos que se ha avanzado, no aceleradamente, pero si de alguna forma satisfactoria para el bien de mucha gente que habita aquí y para otra gente que está llegando a nuestra región. (Conversación personal con Carlos Martínez Cuellar, director de Piamonte estéreo, 2 de julio de 2014) 
Figura 12. Fotografía de Carlos Martínez Cuellar, ex director de Piamonte estéreo 88.4 FM

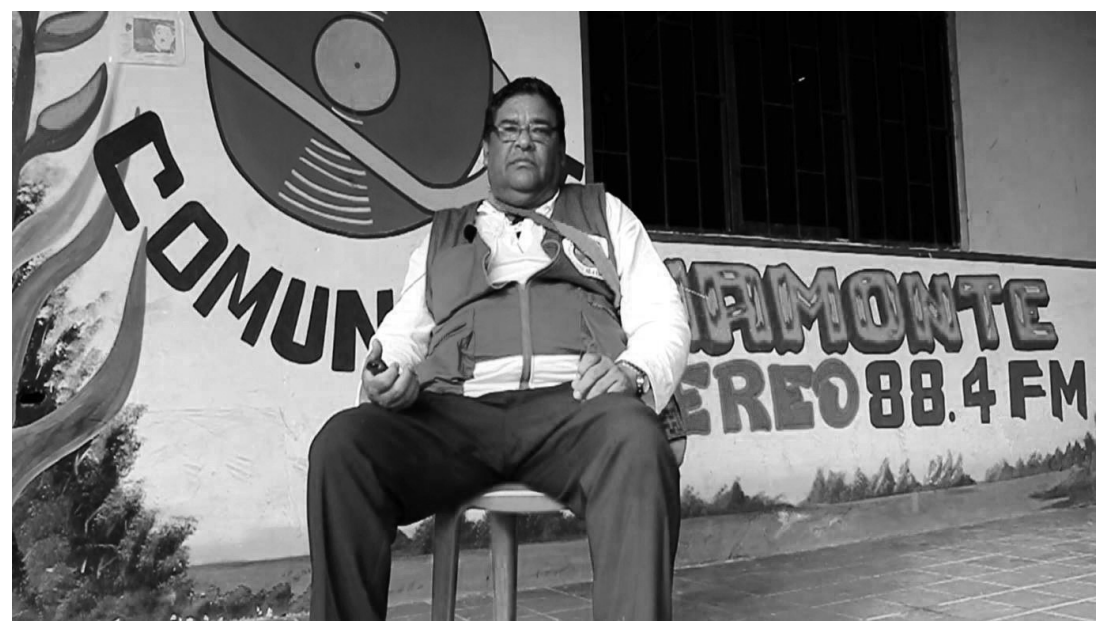

Fuente: Archivo grupo de investigación.

A Carlos lo habíamos conocido seis meses antes en una temporada de vacaciones; él, siempre presto a atendernos, nos dice por celular (que ya funciona) que lo esperemos unos minutos mientras llega a las instalaciones de la emisora, la cual en ese momento estaba cerrada porque desde hacía casi tres horas se había suspendido el servicio de energía eléctrica en el municipio.

Nos sentamos a esperar en una panadería frente a la emisora. Al llegar, Carlos saluda expresivo y dice: "le fallé hombre, no pude conseguir apoyo de la Alcaldía sobre lo que habíamos hablado, solo logré el hospedaje, pero no se pudo la alimentación”. Carlos se refería a nuestro primer encuentro, seis meses antes, cuando habíamos hablado de la posibilidad de abrir espacios de prácticas profesionales para estudiantes universitarios en la emisora. Frente a la disculpa, le expresamos que no importaba, que él no fallo en nada, que sabemos lo difícil que es hacer gestión comunitaria y que de igual manera lo importante era saber que todavía existe la posibilidad de acercar a los jóvenes comunicadores y periodistas a las experiencias de estas regiones de las que muy pocos se acuerdan. Igual, aquí estamos, nuevamente, para conversar. 
Carlos nos contó lo que había pasado con la emisora en los últimos meses. Nos dijo que en estas épocas de invierno tenían serios problemas porque los rayos caían en la antena y ya habían quemado tres transmisores, que son el "alma" de la emisora, pues es el aparato que les permite radiodifundir la señal, además de ser uno de los equipos más costosos. Luego de unos minutos de historias, le propusimos a Carlos ir grabando la conversación: "como ustedes quieran, eso no es sino que pregunten que yo les contesto lo que pueda...", señaló.

Alistamos los aparatosos equipos con los que andamos: cámara profesional prestada, cables de sonido, micrófono. Le propusimos ubicarnos al frente de la sede de Piamonte estéreo para aprovechar lo que quedaba de luz día. Iniciando la grabación, y como suele suceder en los casos de registro en video, el ritmo de la narración se perdió. La espontaneidad inicial de Carlos se diluyó frente a la cámara.

Hicimos la primera entrevista y nos despedimos, no sin antes coordinar para el día siguiente un recorrido hacia el cerro donde se encuentra ubicada la antena de transmisión. Como había sucedido en Yurayaco, el sitio de la torre de transmisión, que por requerimiento técnico del Ministerio de las TIC debe estar ubicado en un lugar alto, se convierte en lugar estratégico para los actores armados del conflicto, que se sitúan en la región:

- ¿A qué hora nos vemos mañana, don Carlos?... - preguntamos.

- Temprano, como a las 8, porque ya a esa hora no está el Ejército... - nos respondió.

Lo que luego confirmamos es que Carlos no tiene prevención con la presencia del Ejército en inmediaciones de la antena de transmisión, pero sí le preocupaba el hecho de que nosotros, visitantes, desconocidos, fuéramos al predio y nos encontráramos con los soldados: "Uno no sabe, alguna cosa puede pasar, sobre todo si llegan con cámaras", nos dijo.

Luego de despedirnos de Carlos fuimos a buscar a Amado Grajales, el gerente de la emisora. Amado es además propietario y gerente de una cooperativa de transporte terrestre y fluvial de pasajeros, de una empresa que hace mantenimiento de las vías del municipio y es dueño de uno de los hoteles (el más prestante) de Piamonte. Amado, se puede 
decir, es "el empresario" de la zona, y nos contó que tiene pensado un proyecto de compra de maquinaria para el mantenimiento vial, ya que no es negocio andar contratando maquinaria "porque allí se va toda la plata”. También proyecta, para el próximo año (2015), "lanzarse por la alcaldía”. En las próximas elecciones: “yo soy prácticamente el único empresario del municipio...”, nos dice.

Figura 13. Fotografía de Amado Grajales, gerente de Piamonte estéreo 88.4 FM y empresario del municipio

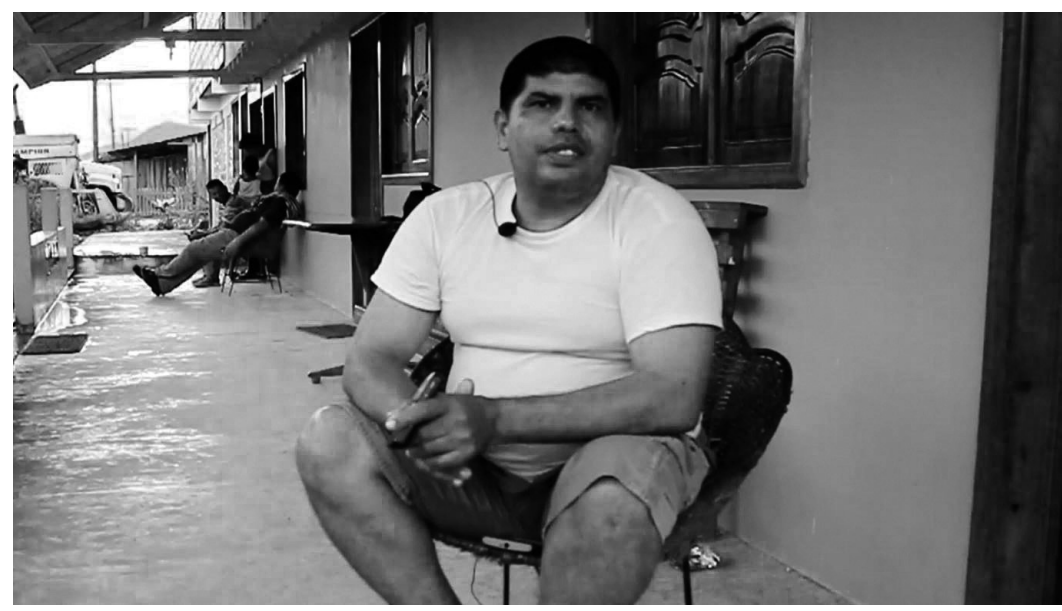

Fuente: Archivo grupo de investigación.

Con Amado aprovechamos las últimas luces del día. Conversamos sobre su participación en la emisora, sobre su trabajo comunitario y sobre cómo se le ocurrió incursionar en el sector de las comunicaciones alternativas. También nos cuenta, un poco a modo de infidencia, los líos que ha tenido con los actores armados de la zona (militares, paramilitares y guerrilleros) por sus labores sociales, y cómo su reconocimiento como líder comunitario le ha salvado la vida, eso y su fe en Dios. Fue evangélico por unos años, "pero el trabajo no me dejó tiempo para continuar con la iglesia...”. Amado es el financiador de Piamonte estéreo, gestor y mentor de Carlos Martínez, el director. Fue quien hizo "las vueltas" de la licencia ante al Ministerio y quien logró la formalización del proyecto frente a las autoridades políticas del municipio, del departamento y de la nación. 


\section{Hacia la antena}

Minutos antes de las 8 de la mañana del 4 de julio llamamos a Carlos, a ver si desayunábamos juntos. Nos dijo que ya estaba en la emisora, pues desde hacía unos días realizaban unos arreglos de infraestructura: se encontraban aislando la cabina del sonido externo. Cuando llegamos a la emisora luego del desayuno (por aquí, como en toda zona campesina del país, el desayuno parece almuerzo: arroz, plátano, huevos, pan, arepa, chocolate... y si lo prefiere, como en Yurayaco, cachama, carne sudada, pollo...) Carlos nos presentó a Jhon Jairo y a Diego (a quién ya habíamos conocido el día anterior, fue él quien "prendió” la emisora cuando llegó la luz): "ellos los van a acompañar hasta la antena”.

Figura 14. Fotografía de Jhon Jairo y Diego, alter comunicadores de Piamonte estéreo 88.4 FM

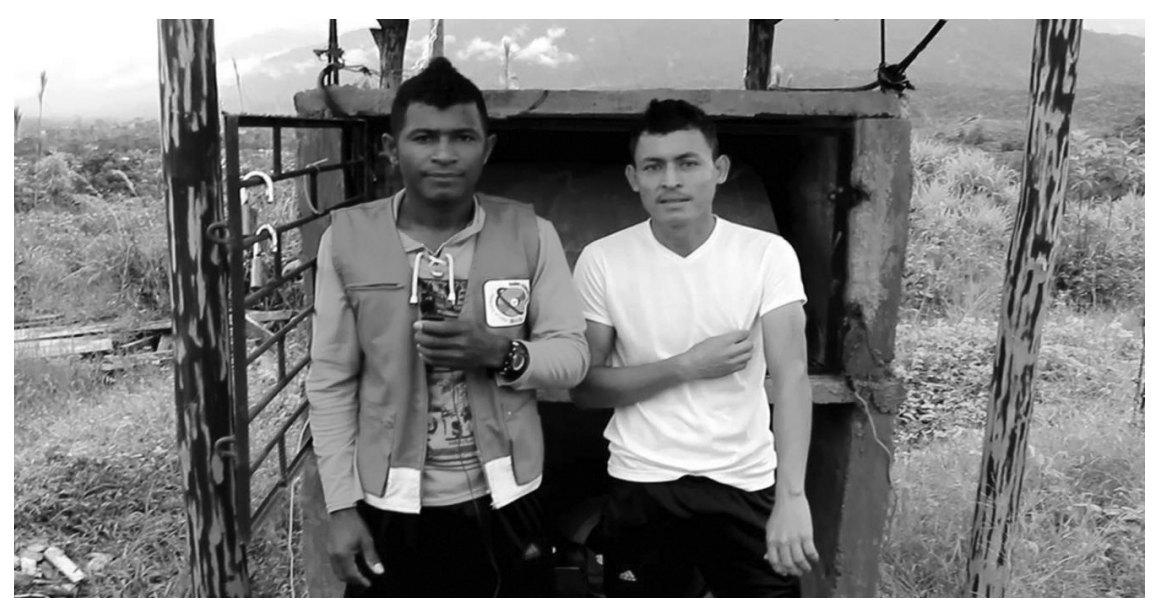

Fuente: Archivo grupo de investigación.

Agradecimos a Carlos, nos despedimos de él y arrancamos camino. Los potreros de la parte plana estaban inundados, eran puro barro. Llegamos a una quebrada que se suele pasar fácilmente. Esta vez la compañera tuvo que pedir ayuda pasar. Jhon Jairo la cogió de la mano y, literalmente, "se lanzaron al agua”, que en la parte más honda les llegaba arriba de la rodilla. La corriente era fuerte. Pasados la quebrada y los potreros, llegó el cerro, completamente encharcado. Las botas se hundían y se pegaban al barro: la subida era por un resbaladero. 
Ya en la antena, Jhon Jairo comenta que realmente el problema que él ve con eso de la emisora comunitaria, es que las personas o entidades que hacen uso de ella no necesariamente cumplen con los compromisos pactados; por ejemplo, es difícil que la Alcaldía responda con los recursos económicos que se compromete a pagar por emitir sus comunicados para la comunidad piamonense: “... y a nombre de que es una emisora comunitaria, es difícil estar exigiendo los pagos”, señala.

Una dificultad seria que tenemos es lo económico; tenemos bastantes personas que mantenemos ahí colaborando de tiempo completo, pero el municipio es pequeño y el comercio no abastece las necesidades [de sostenimiento financiero] de la radio. Las pautas que tenemos son muy pocas y al tratarse de radio comunitaria siempre la comunidad se le colabora pasando información con una tarifa muy baja; por ser radio comunitaria se les puede hacer el descuento del cincuenta por ciento. Pero cuando se nos dañan los trasmisores no tenemos con qué hacerlos arreglar... Entonces, pienso que esa es una gran dificultad, que no tenemos un apoyo, digamos, de las instituciones, pues es muy difícil para que ellas pauten; pasan de pronto algunos informes, pero es muy bajita la tarifa. Pero a pasar de eso, con el esfuerzo de nosotros hemos tratado de sacar adelante esta emisora y ahí la llevamos. (Conversación personal con Jhon Jairo, alter comunicador de Piamonte estéreo, 2 de julio de 2014)

Este joven, Técnico en Ingeniería de Petróleos, uno de los oficios de mayor auge en la zona por la presencia de compañías petroleras como Gran Tierra, también manifiesta su dificultad personal para participar constantemente de las actividades de la emisora, pues no hay recursos y como el trabajo es voluntario, sin pago alguno más allá de la satisfacción y el reconocimiento de la comunidad, por temporadas le toca desplazarse a los pozos petroleros del Bajo Putumayo para buscar trabajo y poder conseguir los recursos para su manutención. De la agricultura, de la pesca y, en general, de las labores del campo, poco hablan estos jóvenes. 
Otra inconformidad tiene que ver con la asignación de los contratos que oferta la Alcaldía Municipal de Piamonte, pues él como tecnólogo dice estar en condiciones de asumir algún trabajo como empleado público o contratista, pero la administración se los asigna a otras personas, inclusive provenientes de otros municipios y departamentos.

Ya en la torre de transmisión, Diego y Jhon Jairo revisan los equipos que se encuentran en el "buncker" (que así le dice Jhon Jairo al cajón de ladrillo y cemento de metro y medio de altura donde se ubica en transmisor). Modulan el sonido, limpian la mugre, revisan las conexiones y nos ofrecen una entrevista en la que hacen énfasis en su labor como comunicadores comunitarios, en las relaciones problemáticas que se presentan con la comunidad a la hora de gestionar recursos para el sostenimiento financiero de la emisora y, de manera general y ambigua, de las dificultades que han tenido que sortear con los actores armados que hacen presencia en la zona:

[Estos temas] no los tratamos directamente, no hablamos mucho del conflicto armado porque dichos personajes que lo hacen, como son las Fuerzas Militares o los grupos al margen de la ley, están acá presentes y eso genera dificultades. La comunidad a veces viene, cuando pasan casos, a pedir el apoyo de la radio comunitaria y tratamos de apoyar, difundir que todos estos conflictos para que tengan alguna solución, pero lo que buscamos es llevar estos casos a las entidades que tienen la competencia de solucionar esos problemas. (Conversación personal con Jhon Jairo, alter comunicador de Piamonte estéreo, 2 de julio de 2014)

De regreso, Carlos nos comenta sobre su preocupación por los equipos que se encuentran en el cerro, que fueron "donados" por la empresa Gran Tierra, petrolera de la zona, requieren mayor seguridad, pues se encuentran muy a la mano de quien quiera llevárselos, "así sea solo por hacer el daño". Carlos nos consulta una idea suya antes de despedirnos: se le ha ocurrido que con algún apoyo, puede ser del municipio, se pueda construir una casa en el terreno de la torre (que fue cedido en comodato por la alcaldía, igual que la sede de la emisora) donde viva alguien. "Se puede crear un proyecto productivo, darle 
unas gallinas a la persona, para que con eso se mantenga... ¿qué les parece?”. Decimos que sí, que buena idea. Habrá que esperar a ver qué se resuelve en este sentido.

Nos despedimos de Carlos, Jhon Jairo y Diego. Ahora iniciamos camino hacía Puerto Caicedo, en el Bajo Putumayo. Allá nos espera Líverman Rengifo, líder de la emisora comunitaria Ocaina estéreo.

\section{Ocaina estéreo: resistencia comunicativa en el Bajo Putumayo}

Municipio de Puerto Caicedo, Bajo Putumayo

Emisora Ocaina estéreo 96.3 FM

Julio de 2014

El 4 de julio salimos de Piamonte, en el sur del Cauca, para dirigirnos hacia el departamento del Putumayo. Por las condiciones de la carretera, los deslizamientos de tierra y las lluvias de julio, hicimos una parada en la casa de la señora Olga, la hija de Taita Paulino, uno de los sabedores y médico tradicional Inga más importantes de la región. Pasamos a saludar y a escampar esa noche, para salir a la mañana siguiente hacia Puerto Caicedo, en el Bajo Putumayo. Estando en la Floresta Castellana, donde habita el Taita Paulino, vimos con la familia el partido Colombia - Brasil, del mundial de fútbol, por Directv, porque en estas lejanías de Colombia, la televisión satelital prepago llegó al tiempo que el agua de acueducto y la luz eléctrica, hace solo un par de años.

Al día siguiente, 5 de julio, retomamos el viaje a las 8 de la mañana, en un recorrido que se nos iba a llevar toda la mañana, iniciando en "moto taxi” desde la Floresta Castellana, a más o menos un kilómetro de la inspección de Mira Flor, Cauca. Nos dirigimos hacia el muelle (puerto) conocido como El Jauno, sobre el Río Caquetá. Allí tuvimos que esperar hasta que se llenara el cupo mínimo de la lancha en la que pasaríamos el Río, que por efecto de las lluvias estaba crecido, torrentoso y fangoso, lo que representaba un peligro importante para los viajeros, para la carga y para el mismo medio de transporte. 
Figura 15. Lanchas sobre el Río Caquetá, sector El Jauno, frontera entre los departamentos del Cauca y Putumayo
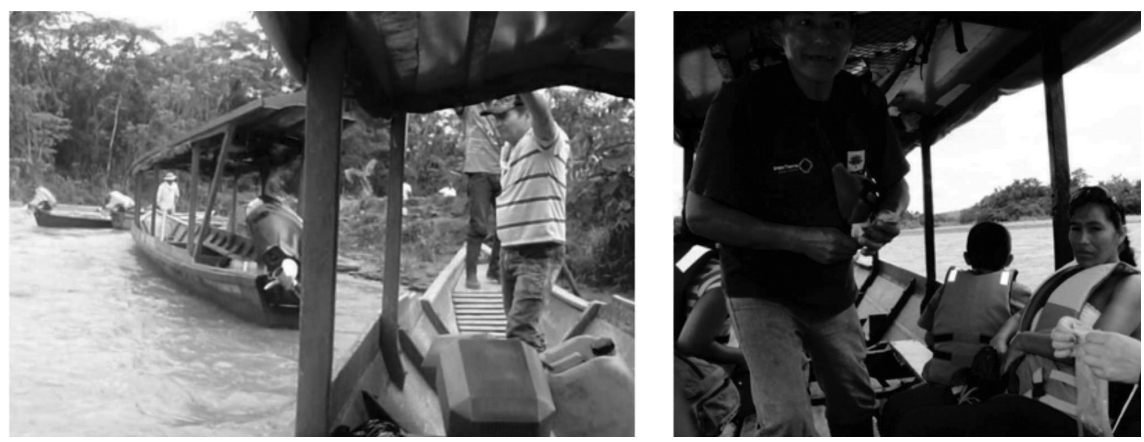

Fuente: Archivo grupo de investigación.

Pasado el río, ahora del lado del Putumayo, en seguida conseguimos camioneta:

- ¿Tiene puestos en cabina?, preguntamos a ver si nos ahorrábamos el zangoloteo de la parte trasera de la camioneta de platón que ha sido adecuada para transporte de pasajeros.

- No, pero ahi atrás van cómodos..., dijo el conductor mientras amarraba las maletas en el maletero del techo.

- Y ¿nos puede dar tiquete?...

- ¿Tiquete?, ¡no!, por este recorrido no damos tiquete...

- Entonces nos puede firmar un recibo; es para poder justificar la plata y que luego nos la repongan en el trabajo..., le pedimos al conductor, quien nos miró con cara de desconcierto...

- ¿Un recibo? Y eso dónde lo cobro o qué..., nos preguntó.

- No, nosotros le pagamos de una vez, pero usted nos hace el favor de firmarnos un recibo por el costo del pasaje..., le aclaramos.

- Bueno, sí, pero hagámosle..., nos dijo mientras nos daba la espalda y se dirigía a la cabina para prender el carro y arrancar camino.

Llegamos a Villa Garzón. En el camino habíamos visto una fuerte presencia de tropas militares que se dedicaban, entre otras cuestiones, a 
vigilar la infraestructura petrolera de la región. En la entrada de uno de los batallones del Ejército que se encuentran a la vera del camino hacia Villa Garzón (el Batallón de Infantería No. 25) se ubicaba un pendón que llamó nuestra atención: junto a la foto de alias "Iván Márquez", comandante miembro del secretariado de las Farc-ep y negociador de esta guerrilla en el proceso de paz de La Habana, Cuba, y de un grupo de guerrilleros que se "camuflan" entre lo que parecen ser hojas de coca, se leía: "No más Farc. 50 años sembrando terror y maldad". Interesante consigna militar en el contexto de un proceso de paz, pensamos, mientras recordábamos la consigna que habíamos leído en algún muro en la inspección de Zabaleta, en el Caquetá: “Comandante Jorge Briceño: estamos cumpliendo". La estrategia de propaganda comunicativa está a la orden del día en estas zonas del país. En Villas tomamos otra camioneta que nos conduciría, ahora sí, a Puerto Caicedo, lugar al que llegaríamos pasado el mediodía.

Figura 16. Pendón / panfleto ubicado en la entrada del Batallón de Infantería No. 25 del Ejército Nacional, en el municipio de Villa Garzón, Putumayo. En el texto se lee: "No más Farc. 50 años sembrando terror y maldad"

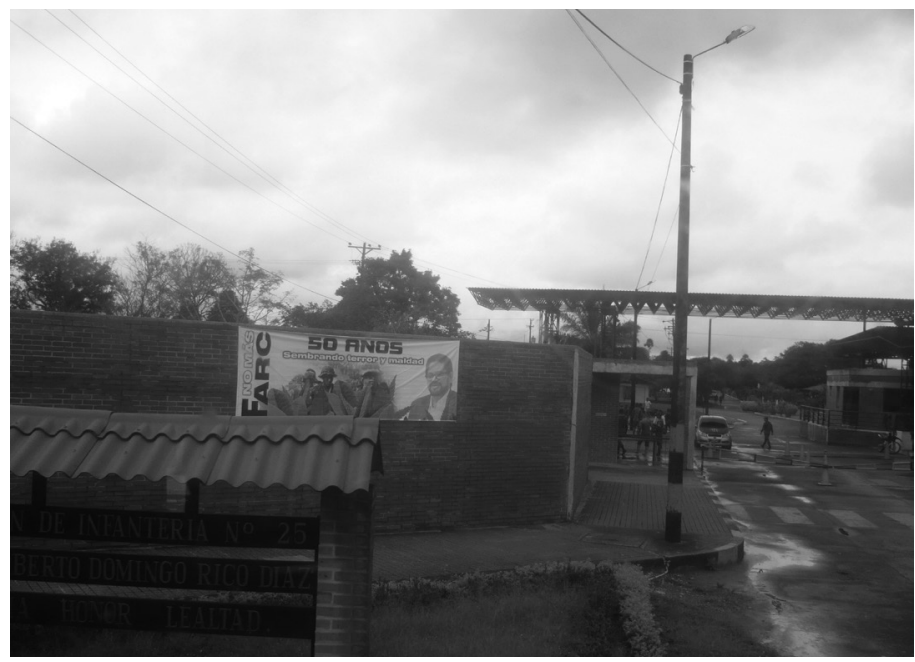

Fuente: Archivo grupo de investigación.

Desde Villa Garzón llamamos nuevamente a Líverman Rengifo, comunicador comunitario, líder de Ocaina estéreo y representante legal 
de la Corporación Nuevo Milenio, organización concesionaria de la emisora ante el Ministerio de las TIC. A Líverman lo estábamos intentando llamar toda la semana para recordarle nuestra llegada, ya que era la única experiencia que no conocíamos previamente y, como suele suceder en estas iniciativas investigativas, hay mucho de desconfianza de la gente hacia los "investigadores que llegan a sacarle información a las comunidades y nunca vuelven".

Algo parecido nos había dicho Líverman, con todas sus razones, la primera vez que hablamos por teléfono con él, unas semanas antes. Lo llamamos "recomendados" por Richard "Pachito" Carlosama, un amigo que vive y desarrolla su trabajo con su comunidad, la Inga, en el Valle de Sibundoy. La idea inicial era trabajar con la experiencia de emisoras indígenas de Sibundoy a la que se encuentra vinculada Pachito, pero él por estos días andaba en el Bajo Putumayo trabajando y estudiando, así que nos recomendó con Líverman, que además era coordinador de la Red de Emisoras Comunitarias del Putumayo, denominada como Red Cantoyaco.

El caso es que llamamos al Líverman durante una semana para recordarle reiteradamente sobre nuestra visita, a pesar de que desde el principio había dicho, aunque un poco prevenido, que sí nos atendería. Y allá le llegamos el sábado 5 de julio, al medio día. Nos dijo que nos esperaba a la una de la tarde en la emisora, que preguntáramos dónde quedaba la estación de Policía y que era por esa misma vía, una cuadra antes, que preguntáramos a cualquiera que todo el mundo daba razón.

A la una estuvimos en la sede de Ocaina. Nosotros íbamos con la expectativa de encontrarnos con "un mechudo medio hippie" que habíamos conocido en Bogotá, unos años antes, en un evento de comunicación y memoria. Al encontrarnos con Líverman y viendo que no era el que traíamos en la memoria, le comentamos sobre nuestra confusión: "Ese debió ser Valdez (Libardo Valdez)... Él trata mucho el tema de la memoria y trabaja mucho con defensores de derechos humanos... Y hace unos años decidió dejar de cortarse el pelo...”, nos dijo.

Luego de las presentaciones, Líverman comenzó a contarnos sobre la experiencia de Ocaina estéreo. Dijo que había sido una iniciativa de la Pastoral Social, de la cual se encargaba el padre Alcides Jiménez hasta que lo mataron los paramilitares en pleno púlpito de la parroquia de 
Puerto Caicedo, el 11 de septiembre de 1998. Ocaina era un proyecto que se articulaba a otros tantos de carácter productivo, pues desde la Pastoral Social se proponía una mirada integral al desarrollo rural. Este conjunto de proyectos inició en 1996, cogió fuerza en 1997 y se debilitó en 1998 con el asesinato del padre Alcides, pero no desapareció, entre otras por la visión que tuvo la comunidad del proceso y por el grupo de líderes que se lograron formar y consolidar en el proceso de la Pastoral.

Figura 17. Afiche de evento de lanzamiento de libro "Semillas de paz”, sobre vida y obra del padre Alcides Jiménez, gestor de la emisora comunitaria Ocaina estéreo, asesinado por paramilitares en septiembre de 1998 en Puerto Caicedo, Putumayo

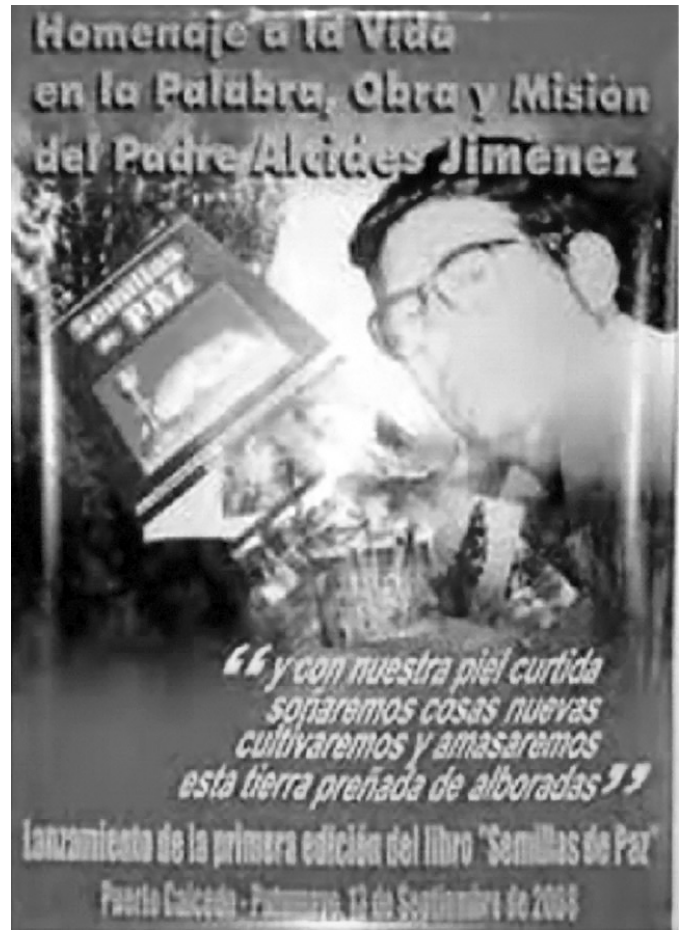

Fuente: Archivo Ocaina estéreo.

Lo primero que nos dijo Líverman es que, como sucede con otros proyectos radiofónicos del sur del país, las lluvias y las tempestades no son muy favorables para el proyecto de la emisora comunitaria. Como ya nos habían comentado en Ingakuna estéreo y en Piamonte estéreo, Líverman 
nos cuenta que han tenido muchas dificultades "con el clima", pues cuando hay borrasca se corre el riesgo de que se dañen los equipos de transmisión que se encuentran en la torre. Esta dificultad, convertida ahora en oportunidad, ha demostrado lo importante que se ha convertido Ocaina estéreo para la comunidad de Puerto Caicedo: “algunas veces que se han dañado los equipos, la comunidad ha apoyado con actividades: bazares, torneos deportivos, donaciones, para restituirlos", dice Líverman, quien también nos cuenta que en el 2009 Ocaina ganó el premio nacional de “mejor desempeño de emisora comunitaria”, promovido por el Ministerio de Cultura en el marco del programa Radios Ciudadanas.

Este premio, entendemos, ha sido un gran incentivo para los gestores de Ocaina y otras experiencias de radio comunitaria en el Putumayo, hasta el punto de lograr vincular múltiples experiencias en la Red de emisoras comunitarias del Putumayo, Cantoyaco. Siendo el representante legal de la Red, Líverman hace énfasis en las múltiples gestiones que los líderes de la emisora han realizado con diferentes empresas, organizaciones e instituciones a nivel nacional e internacional, con el fin de lograr recursos para consolidarla como una propuesta departamental de medios, con enfoque alternativo y ciudadano.

Figura 18. Equipos de producción radiofónica entregados a la Red Cantoyaco, en el marco de convenio con Ecopetrol

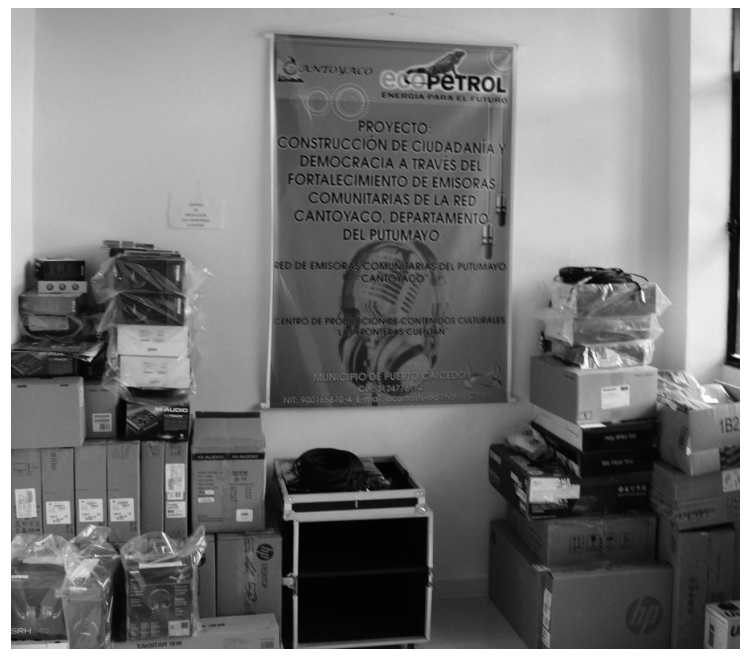

Fuente: Archivo grupo de investigación. 
Gracias a estas gestiones, la Red Cantoyaco hoy cuenta con un estudio para la producción profesional de contenidos, ubicado en la sede de Ocaina estéreo, y con equipos de última tecnología para el desarrollo de las actividades proyectadas: "Esperamos poder terminar la construcción del segundo piso [de la edificación donde hoy se ubica el estudio de la Red Cantoyaco], para poner a funcionar allí a Ocaina estéreo", dice Líverman mientras nos hace un recorrido por la emisora.

Las instalaciones de la emisora constituyen un pequeño complejo de construcciones donde tienen sede la Corporación Nuevo Milenio (concesionaria de la licencia), la Red Cantoyaco y Ocaina estéreo. Este complejo es muestra de la visión integral que los gestores de los procesos comunitarios de Puerto Caicedo han tenido frente a su trabajo, debido a que junto con la emisora se han sostenido otros proyectos, como el de producción de champús, jabones y otros productos de aseo fabricados con productos naturales propios de la Amazonía colombiana. Otro proyecto es el de Delicias Amazónicas, donde la Asociación de Recuperadores Ambientales e Industriales de Productos Amazónicos para la Soberanía Alimentaria, Raizal, produce néctares de frutas como arazá, cocona y copoazú. Todos estos proyectos alternos contribuyen al sostenimiento de Ocaina.

Luego de recorrer las instalaciones, Líverman nos cuenta de su experiencia como formador. Desde Ocaina han desarrollado procesos de formación radiofónica con las comunidades, a fin de involucrarlas de manera activa en el desarrollo, sostenimiento y continuidad económica, social y política de la emisora.

La última convocatoria pensamos no abrirla porque había mucha oferta del Sena para 'vigilancia privada', 'auxiliar petrolero' y cuestiones de esas, pero con Valdez dijimos: 'abramos el curso' y nos llegaron más de 50 personas, entre ellas como 10 niños... En esos procesos uno aprende mucho. Por ejemplo en un taller de los últimos, Valdez propuso una actividad lúdica y dijo 'vamos a hablar de las madres' y a una chica se le había muerto en esos días la mamá... No sabíamos qué hacer. Ahí nos quedó la enseñanza de que lo primero son las personas, hay que saber con quiénes estamos en estos procesos... (Conversación personal con Líverman Rengifo, 5 de julio de 2014) 
Frente a la formación, desde Ocaina se tiene pensado gestionar un proceso con la Universidad Pontificia Bolivariana (UPB), que ofrece programas semi presenciales en la zona, para implementar capacitaciones en comunicación social. "También hay gestiones con otras instituciones y personas, como Alma Montoya, una gran amiga que nos apoya con su conocimiento y sus gestiones desde Bogotá”, señala.

Antes de despedirnos ese día, Líverman nos muestra uno de sus "tesoros escondidos": un transmisor remoto que les permite trabajar en las veredas, en la zona rural del municipio.

Nosotros tenemos un proyecto de Ocaina Andariega, donde realizamos la transmisión directamente en las comunidades. Una vez al mes vamos a las comunidades donde nos invitan y trabajamos el tema de la memoria: cuándo se fundó la vereda, las historias de las juntas de acción comunal, etc. Ese día en la comunidad hay como un bazar, una fiesta. Jugamos futbol, nuestro equipo siempre pierde, pero como somos los que transmitimos, entonces siempre ganamos por goleada, ja ja ja, ese día hay música, comida. Ese día nos vamos hasta las 10 u 11 de la noche en la actividad... (Conversación personal con Líverman Rengifo, 5 de julio de 2014)

Figura 19. Fotografía de Líverman Rengifo en la sede de la emisora comunitaria Ocaina estéreo 96.3 FM de Puerto Caicedo, Putumayo

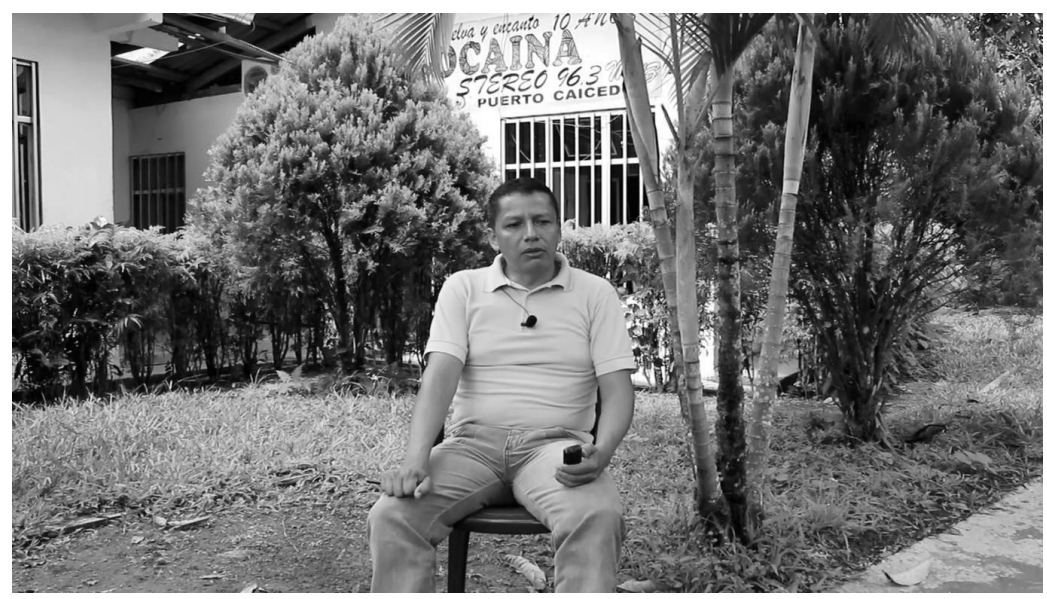

Fuente: Archivo grupo de investigación. 
Así nos despedimos, esperando viajar al día siguiente a Mocoa, capital del departamento del Putumayo, donde esperábamos conversar con Libardo Valdez y Richard Carlosama, miembros de la Red Cantoyaco. Ellos se encontraban en Puerto Asís, a unos 20 minutos en camioneta desde Puerto Caicedo, pero decidimos verlos en Mocoa, ciudad a la que ellos se dirigirían también al día siguiente, luego de terminar sus clases de la Licenciatura en Etno-educación, en la Universidad Pontificia Bolivariana, sede Puerto Asís. Infortunadamente por las cosas del clima, el compañero Valdez no pudo llegar y Richard, que sí llegó, tuvo que salir corriendo para el Valle de Sibundoy, en el alto Putumayo. Conversamos en el desayuno:

En algunos momentos nos enteramos de lo que pasa en el proceso de paz por informaciones que se tienen desde los mismos medios, y el problema es que tampoco hay información sobre ello, se especula, se entra a especular sobre qué podría ser, pero realmente se está desarrollando un proceso a espaldas del país, a espaldas de las víctimas, pero... no sé, también si obedece solamente a una estrategia para permanencia en el poder de los que están ahorita, pues digamos uno ve un proceso de paz y con firmar la paz con una guerrilla que ha victimizado tanto, que ha dejado tanto daño, no justificando a los unos ni a los otros, porque igual cualquier actor armado en Colombia ha estado dejando a la población en el medio, sin herramientas, no sé qué tanto logro pueda darse más adelante, pero en lo que tiene que ver con la información, pues no conocemos a ciencia cierta lo que pasa, porque no hay información sobre ello, me parece más bien que se ha estado dilatando procesos para otros fines... (Conversación personal con Richard Carlosama, alter comunicador del Valle de Sibundoy, julio de 2014)

\section{Cátedra de realidad colombiana}

Una noche en Puerto Caicedo salimos del hotel buscando alguna comida ligera. En el camino hacia la emisora, habíamos visto un sitio en la plaza de mercado donde vendían ensaladas de frutas, jugos, choripapas, 
hamburguesas con patacón. Para allá nos dirigimos. Pedimos de comer y nos sentamos en una de las mesas ubicadas en el frente del local, sobre el andén. En los alrededores del sitio, que quedaba ubicado en uno de los sectores comerciales del centro de Puerto Caicedo, algo así como una "zona rosa", habían cantinas, tabernas y bares que tronaban música popular mezclada con vallenatos y reggaetón. Una buena cantidad de personas y motos circulaban por la zona.

Poco antes de las 8 de la noche, a unos 50 metros de donde estábamos ubicados, en una taberna detonaron unos disparos: primero una seguidilla como de 5 o 6 , y segundos después otra, de 3 o 4 tiros. La gente corrió hacia la esquina para protegerse. Mientras nos resguardábamos en un pasillo del local, vimos, aunque del susto no lo podríamos confirmar, a un hombre bajo y gordo vestido de negro que huía, pistola en mano, por la mitad de la calle, en dirección contraria a dónde estábamos. La compañera de viaje se quedó sentada. Luego me dijo que el susto lo que hacía era bloquearla, y me contó la historia de una balacera que tuvo que vivir hace unos años en "un metedero" del municipio de Aponte, en Nariño.

Pasado el susto, que duró unos segundos, la gente comenzó a asomar la cabeza y a agolparse en la esquina del crimen. Nosotros mismos fuimos a chismocear: "le dieron a la mona que se está quedando en la casa de don Andrés...", dijo un chico a sus amigos. "Ya se llevaron a la muchacha en una moto... unos manes la alzaron y se la llevaron para el hospital... tenía una herida en la pierna...", dijo un señor que minutos antes se encontraba viendo televisión en un pasillo del mismo local donde habíamos ido a comer. "Parece que hay otro adentro...", señaló otro paisano que estiraba el pescuezo en la acera del frente, sin atreverse a pasar la calle e ir a confirmar su versión.

Algunas personas entraban, fisgoneaban y salían del local, una taberna llamada La Esmeralda, de esas a las que les pintan el letrero grande y colorido en la pared, de esas que se toma parte del andén para ubicar una barra, que saca una columna de sonido a la calle y que tiene la publicidad de Aguardiente del Putumayo colgada en los bordes del techo de zinc.

La Policía llegó 15 minutos después: “ahí llegaron, por fin...”, dijo alguien mientras la dueña del local donde comíamos se persignaba y se 
devolvía al negocio. Los agentes no se demoraron 10 minutos en el lugar. Una vez revisaron lo que podría haber pasado, se fueron. Luego las meseras del local sacaron un balde con agua y se lo echaron a la sangre, trapearon y organizaron mesas y asientos. A las 8:30 de esa noche ya la música estaba nuevamente tronando y los tumultos de gentes se habían dispersado. Si alguien que no hubiese estado en la balacera pasara a esa hora, casi que con seguridad se podría decir que no se enteraría del atentado, de la sangre, de los heridos y, quizás, de los muertos...

Nosotros terminamos la comida mientras recordábamos historias. La compañera fue a pagar y se detuvo a hablar con la dueña del local. De vuelta, indignada, me cuenta:

Dice la señora que esta es la cuarta mujer abaleada esta semana...

- No jodás, ¿̇y sabe por qué...? le pregunté.

- Dicen que son mujeres de guerrilleros, y que por eso las están matando.

Al día siguiente pasamos por el frente de la taberna La Esmeralda, como a las 12 del mediodía. Íbamos para la agencia de transportes para comenzar el viaje hacía Mocoa. En la taberna, a esa hora, ya había algunas cervezas en las mesas del local, como si no hubiera pasado nada la noche anterior. Uno pensaría que, frente a lo acontecido, el local estaría cerrado, sellado, y que los investigadores del CTI de la fiscalía estarían "haciendo la investigación”. Pero no. El local abierto, la música sonando y los clientes contentos. Una pura cátedra de realidad colombiana. 
